Article

\title{
Role of the Support Effects on the Catalytic Activity of Gold Clusters: A Density Functional Theory Study
}

\author{
Min Gao ${ }^{1}$, Andrey Lyalin ${ }^{1,2, \star}$ and Tetsuya Taketsugu ${ }^{1}$ \\ ${ }^{1}$ Division of Chemistry, Graduate School of Science, Hokkaido University, Sapporo 060-0810, Japan; \\ E-Mails: gaomin1986@gmail.com (M.G.); take@ sci.hokudai.ac.jp (T.T.) \\ ${ }^{2}$ V. A. Fock Institute of Physics, St Petersburg State University, Petrodvorez 198504, Russia \\ * Author to whom correspondence should be addressed; E-Mail: lyalin@ mail.sci.hokudai.ac.jp; \\ Tel.: +81-0-80-3292-3010; Fax: +81-0-11-706-4921.
}

Received: 6 October 2011; in revised form: 31 October 2011 / Accepted: 16 November 2011 / Published: 17 November 2011

\begin{abstract}
It is demonstrated that the support effects play a crucial role in the gold nanocatalysis. Two types of support are considered-the "inert" support of hexagonal boron nitride (h-BN) with the $\mathrm{N}$ and $\mathrm{B}$ vacancy defects and the "active" support of rutile $\mathrm{TiO}_{2}(110)$. It is demonstrated that $\mathrm{Au}$ and $\mathrm{Au}_{2}$ can be trapped effectively by the vacancy defects in h-BN. In that case, the strong adsorption on the surface defects is accompanied by the charge transfer to/from the adsorbate. The excess of the positive or negative charge on the supported gold clusters can considerably promote their catalytic activity. Therefore gold clusters supported on the defected h-BN surface can not be considered as pseudo-free clusters. We also demonstrate that the rutile $\mathrm{TiO}_{2}(110)$ support energetically promotes $\mathrm{H}_{2}$ dissociation on gold clusters. We show that the formation of the $\mathrm{OH}$ group near the supported gold cluster is an important condition for $\mathrm{H}_{2}$ dissociation. We demonstrate that the active sites towards $\mathrm{H}_{2}$ dissociation on the supported $\mathrm{Au}_{n}$ are located at corners and edges of the gold cluster in the vicinity of the low coordinated oxygen atoms on $\mathrm{TiO}_{2}(110)$. Thus catalytic activity of a gold nanoparticle supported on the rutile $\mathrm{TiO}_{2}(110)$ surface is proportional to the length of the perimeter interface between the nanoparticle and the support.
\end{abstract}

Keywords: nanocatalysis; gold clusters; support effect; interface effect; oxygen activation; hydrogen dissociation 


\section{Introduction}

Since the pioneering work of Haruta on the oxidation of carbon monoxide on small gold nanoparticles supported by metal oxides [1], an extensive interest has been devoted to understanding the catalytic properties of gold. Such an interest is stipulated by the fact that gold nanoparticles are catalytically active even at room temperatures and demonstrate extraordinary selectivity. This feature makes gold clusters very attractive for a wide range of industrial, chemical and environmental applications [2-4].

Two types of catalytic reactions on gold nanoparticles-oxidation by $\mathrm{O}_{2}$ and hydrogenation by $\mathrm{H}_{2}$ - are extremely important for applications. The most explored types of oxidation reaction include the oxidation of carbon monoxide at mild temperatures, alcohol oxidation, the direct synthesis of hydrogen peroxide and alkene epoxidation; see, e.g., References [1,5-11] and references therein. Heterogeneously catalyzed hydrogenation is another type of reactions where gold nanoparticles have shown their great potential as catalysts. It has been demonstrated experimentally that gold nanoparticles supported on metal oxides such as $\mathrm{SiO}_{2}, \mathrm{Al}_{2} \mathrm{O}_{3}, \mathrm{TiO}_{2}, \mathrm{ZnO}, \mathrm{ZrO}_{2}$, and $\mathrm{Fe}_{2} \mathrm{O}_{3}$ are effective catalysts for selective hydrogenation of several classes of organic molecules, including $\alpha, \beta$-unsaturated aldehydes, unsaturated ketones, and unsaturated hydrocarbons [12-21]. Moreover, supported gold nanoparticles are very selective for the direct formation of hydrogen peroxide from $\mathrm{H}_{2} / \mathrm{O}_{2}$ mixtures [9].

In spite of intensive theoretical and experimental studies the origin of catalytic activity of gold nanoparticles remains elusive and has yet to be fully understood. It is commonly accepted that several factors can influence the catalytic activity of gold nanoparticles. One of them is the size effect. It has been shown that the unique properties of gold in oxidation reactions emerge when the size of catalytic particles decreases down to 1-5 nm, while larger sized particles are catalytically inactive [5]. It has been shown that small gold clusters consisting of a few atoms can also possess extraordinarily high catalytic activity [22,23]. This is the regime where each atom counts, physical and chemical properties of clusters are extremely size sensitive and cannot be deduced from those known for larger sizes $[4,24,25]$. On the one hand, the size effects in nanocatalysis are determined by quantum effects, resulting from the spatial confinement of the valence electrons in the cluster [4]; on the other hand, in such clusters a dominant fraction of atoms are under-coordinated (in comparison with the bulk), hence they exhibit an enhanced chemical reactivity [4,26,27].

The charge state of the gold nanoparticles can considerably influence their reactivity [11,28]. For example, in the case of the negatively charged gold nanoparticles, an extra electron from the gold readily transfers to the anti-bonding $2 \pi^{*}$ orbital of the adsorbed $\mathrm{O}_{2}$, which weakens the $\mathrm{O}-\mathrm{O}$ bond and activates oxygen molecule for further catalytic reaction; see, e.g., References [10,11,29-31] and references therein. Such mechanism of the charge-transfer-mediated activation of $\mathrm{O}_{2}$ by gold clusters has been intensively studied [32-35]. On the other hand, the positive charge accumulated on the gold can promote adsorption of some reactants, such as $\mathrm{CO}$ and hydrocarbons [36,37].

Interaction with the support material is another important factor that considerably influences the reactivity of gold nanoparticles [4,38]. Most of the experimental studies have been performed for gold nanoparticles supported on various metal oxides, such as $\mathrm{MgO}, \mathrm{ZnO}, \mathrm{TiO}_{2}, \mathrm{ZrO}_{2}, \mathrm{Al}_{2} \mathrm{O}_{3}, \mathrm{Fe}_{2} \mathrm{O}_{3}$, see, e.g., Reference [2] and references therein. It was demonstrated that the catalytic activity of gold nanoparticles strongly depends on the type of the support material [2,5,39]. Often, an electron transfer 
from the support to the gold cluster promotes its catalytic activity because it opens a route for an extra charge transfer to the adsorbed $\mathrm{O}_{2}$. Catalytic activity of the supported nanoparticles can also be promoted by defects in the support material. Defects can trap the metal nanoparticle and enhance charge transfer between the support and the nanoparticle. Thus, it was demonstrated that $\mathrm{Au}_{8}$ clusters supported on the $\mathrm{MgO}(100)$ surface rich of F-center defects show high catalytic activity, while $\mathrm{Au}_{8}$ deposited on the defect-poor $\mathrm{MgO}(100)$ surface are inert [40,41]. Defects are not the only factor responsible for charging of the supported metal nanoparticles. Recently, it was demonstrated that the charge accumulated on the supported gold nanoparticle can be tuned by varying the thickness of the metal oxide layer deposited on the metal support [42-46]. Thus, the support effects can play even larger role in gold nanocatalysis than the particle size.

In the present work we demonstrate that the charge transfer from the support to the deposited gold clusters is not the only mechanism responsible for the promotion of the cluster's catalytic activity. Two types of support will be considered - the hexagonal boron nitride ( $\mathrm{h}-\mathrm{BN}$ ) with $\mathrm{N}$ and $\mathrm{B}$ vacancy defects and the rutile $\mathrm{TiO}_{2}(110)$. Using these two examples we show that the support effects on the catalytic activity of gold clusters can be rather diverse and can have different origins.

It is commonly accepted that "inert" supports, such as, h-BN do not affect the electronic and geometric structure of the supported clusters, and hence such clusters can be considered as pseudo-free. This suggestion is widely used to study intrinsic properties of metal clusters that are free from the support effects [6]. Indeed, h-BN is an electrical insulator with a wide band gap $(\sim 5.8 \mathrm{eV})$ and high thermal and chemical stability $[47,48]$. It is unlikely that such a support can promote an electron transfer to or from the deposited gold nanoparticle and influence their physical and chemical properties.

Recently, it has been demonstrated experimentally that small gold clusters deposited on h-BN support are efficient and robust catalysts [6]. However, very little attention has been paid to theoretical investigations concerning the role of the h-BN support on the catalytic properties of gold. Whether the origin of catalytic activity of gold clusters supported on h-BN surface derives from the cluster itself, or h-BN support can modify or tune catalytic properties of gold?

Contrary to the case of the "inert" h-BN support, the rutile $\mathrm{TiO}_{2}(110)$ surface is considered as an active surface that can even possess catalytic properties itself. It has been found experimentally that catalytic activity of gold nanoparticles supported on the rutile $\mathrm{TiO}_{2}(110)$ surface towards $\mathrm{H}_{2}$ dissociation depends on the number of gold atoms located at the perimeter nanoparticle-support interface, irrespective of the cluster size [38]. It has been also shown that the active sites for the $\mathrm{H}_{2}+\mathrm{O}_{2}$ reaction over a $\mathrm{Au} / \mathrm{TiO}_{2}$ nanoparticle catalyst are located at dual perimeter sites at the interface between $\mathrm{Au}$ and $\mathrm{TiO}_{2}$ [49]. To the best of our knowledge there are only few theoretical studies concerning the role of the support on the processes of adsorption and dissociation of molecular hydrogen on the supported gold nanoparticles [50-52]. In Reference [50] the authors performed an elegant theoretical study on elucidation of active sites for $\mathrm{H}_{2}$ adsorption and activation on $\mathrm{Au}_{13}$ cluster supported on the anatase $\mathrm{TiO}_{2}(001)$ surface. It has been shown that $\mathrm{Au}$ atoms that are active for $\mathrm{H}_{2}$ dissociation must have a net charge close to zero, be located at corner or edge low coordinated positions, and not be directly bonded to the support [50]. An important role of the low coordinated oxygen atoms at the nanoparticle/TiO interface has been discussed [52]. In Reference [51] it was shown that small two-dimensional $\mathrm{Au}$ nanoparticles supported on $\mathrm{TiC}(001)$ can dissociate $\mathrm{H}_{2}$ in a more efficient way than when supported 
on oxides. The active sites for $\mathrm{H}_{2}$ dissociation on $\mathrm{Au} / \mathrm{TiC}(001)$ are located at the particle edge and in direct contact with the underlying substrate [51]. In the present work we clarify how hydrogen molecule adsorbs and dissociates on the supported gold nanoparticles.

We demonstrate that the support effects are very important in the gold nanocatalysis. Even the "inert" h-BN support, if it contains point defects, can promote or quench the catalytic properties of gold in oxidation reaction by $\mathrm{O}_{2}$. Therefore gold clusters supported on the defected h-BN surface can not be considered as pseudo-free clusters. We demonstrate that rutile $\mathrm{TiO}_{2}(110)$ support energetically promotes $\mathrm{H}_{2}$ dissociation on gold clusters. We show that the formation of the $\mathrm{OH}$ group near the supported gold cluster is an important condition for $\mathrm{H}_{2}$ dissociation and the conventional charge transfer mechanism does not play an important role for $\mathrm{H}_{2}$ dissociation. The considered phenomena can be particularly important for understanding the mechanisms of the catalytic activity of the supported gold clusters in oxidation reactions by $\mathrm{O}_{2}$ and hydrogenation reactions by $\mathrm{H}_{2}$.

\section{Computational Details}

The calculations are carried out using density-functional theory (DFT) with the gradient-corrected exchange-correlation functionals of $\mathrm{Wu}$ and Cohen (WC) [53] and Perdew, Burke and Ernzerhof (PBE) [54] for $\mathrm{O}_{2} \mathrm{Au}_{n} / \mathrm{h}-\mathrm{BN}$ and $\mathrm{H}_{2} \mathrm{Au}_{n} / \mathrm{TiO}_{2}(110)$ systems, respectively. The choice of DFT functionals is stipulated by the fact that WC gives significant improvements for lattice constants, crystal structures, and surface energies over the most popular PBE functional, while PBE remains superior for the energetics of covalent and noncovalent bonds [55]. In particular, the PBE functional demonstrates very poor performance for the layered-systems like graphite or h-BN, whose distances between the layers are determined by rather weak interactions [55]. Thus, in the case of h-BN lattice the PBE functional demonstrate only marginal binding of the hexagonal layers along "c", while WC provides very accurate results that are close to experiment [55]. On the other hand PBE can reproduce well the tetragonal rutile $\mathrm{TiO}_{2}$ structure, and therefore it has been selected to treat $\mathrm{H}_{2} \mathrm{Au}_{n} / \mathrm{TiO}_{2}(110)$ system.

The atom-centered, strictly confined, numerical basis functions [56,57] are used to treat the valence electrons of $\mathrm{H}\left(1 s^{1}\right), \mathrm{B}\left(2 s^{2} 2 p^{1}\right), \mathrm{N}\left(2 s^{2} 2 p^{3}\right)$, O $\left(2 s^{2} 2 p^{4}\right)$, Ti $\left(4 s^{2} 3 d^{2}\right)$ and $\mathrm{Au}\left(6 s^{1} 5 d^{10}\right)$. Double- $\zeta$ plus polarization function (DZP) basis sets are used for $\mathrm{B}, \mathrm{N}, \mathrm{O}, \mathrm{Ti}, \mathrm{Au}$ and triple- $\zeta$ plus polarization function (TZP) for H. Basis set for hydrogen was optimized with the use of the Nelder-Mead simplex method [58] according to the procedure described in Reference [57]. The core electrons are represented by the Troullier-Martins norm-conserving pseudopotentials [59] in the Kleinman-Bylander factorised form [60]. Relativistic effects are taken into account for Au.

In the present work, the h-BN lattice has been optimized using the Monkhorst-Pack [61] $10 \times 10 \times 4 \mathrm{k}$-point mesh for Brillouin zone sampling. The calculated lattice parameters $\mathrm{a}=\mathrm{b}=2.504 \AA$ and $\mathrm{c}=6.656 \AA$ Aare in excellent agreement with the experimental values of $\mathrm{a}=\mathrm{b}=2.524 \pm 0.020 \AA$ and $\mathrm{c}=6.684 \pm 0.020 \AA$, reported in Reference [62]. The h-BN surface is represented by the two-layer slab containing $7 \times 7$ unit cells ( 98 units of BN per slab) with the surface area of $3.07 \mathrm{~nm}^{2}$. The bottom layer in the h-BN slab is fixed while the top layer is fully relaxed. The rutile lattice was optimized using the $6 \times 6 \times 9 \mathrm{k}$-point mesh. The calculated lattice parameters $\mathrm{a}=4.594 \AA$ and $\mathrm{c}=2.959 \AA$ are in agreement with the experimental values of $\mathrm{a}=\mathrm{b}=4.587 \AA, \mathrm{c}=2.954 \AA$ at $15 \mathrm{~K}[63,64]$. The optimized lattice of the bulk rutile was used to construct slabs for the $\mathrm{TiO}_{2}(110)$ surface. The six-layer slab containing four 
units of $\mathrm{TiO}_{2}$ represents the element of the (110) rutile face with the surface area of $\sqrt{2} \mathrm{a} \times \mathrm{c}$. For rutile surface the bottom two layers in the slab are fixed, and all other atoms are fully relaxed. In the present work we study adsorption of $\mathrm{Au}_{n}$ clusters containing $n=1,2,8$ and 20 atoms on the rutile (110) surface. In the case of $\mathrm{Au}$ and $\mathrm{Au}_{2}$ the $\mathrm{TiO}_{2}(110)$ surface is modeled by the $\mathrm{p}(2 \times 5)$ slab $\left(40\right.$ units of $\mathrm{TiO}_{2}$ per slab), while for $\mathrm{Au}_{8}$ and $\mathrm{Au}_{20}$ we use $\mathrm{p}(3 \times 6)\left(72\right.$ units of $\left.\mathrm{TiO}_{2}\right)$ and $\mathrm{p}(4 \times 9)\left(144\right.$ units of $\left.\mathrm{TiO}_{2}\right)$ slabs, respectively. The periodically replicated slabs for $\mathrm{h}-\mathrm{BN}$ and $\mathrm{TiO}_{2}(110)$ surfaces are separated by the vacuum region of $25 \AA$. Only the $\Gamma$ point is used for sampling the Brillouin zone of the slabs due to the large size of the supercell.

The cluster geometries have been determined with the use of the cluster fusion algorithm [65] which belongs to the class of genetic global optimization methods. This method has been successfully used in order to find the optimized geometries of various types of metal clusters [66-68]. Additionally, the global reaction route mapping (GRRM) technique within the scaled hypersphere search (SHS) method has been used in order to find equilibrium structures [69-71]. The optimized structures of the gold clusters are in a good agreement with those reported in previous theoretical studies; see, e.g., References [30,72-75]. The most stable isomers of gold clusters have been further optimized on the support starting from the several (up to 15) initial orientations and positions of the cluster on the surface.

All calculations have been carried out with the use of the SIESTA package [76-78]. Within the SIESTA approach, the basis functions and the electron density are projected onto a uniform real-space grid. The mesh size of the grid is controlled by an energy cutoff, which defines the wavelength of the shortest plane wave that can be represented on the grid. In the present work the energy cutoff of $200 \mathrm{Ry}$ is chosen to guarantee convergence of the total energies and forces. The self-consistency of the density matrix is achieved with a tolerance of $10^{-4}$. For geometry optimization the conjugate-gradient approach was used with a threshold of $0.02 \mathrm{eV}^{-1}$. The atoms in molecules method of Bader (AIM) has been used for charge analysis $[79,80]$. The electron density has been plotted using XCRYSDEN visualisation program [81].

To validate our approach we have calculated the dissociation energies and interatomic distances for several diatomic molecules. Our calculations demonstrate that the dissociation energy, $D_{e}$, and bond length in $\mathrm{H}_{2}(4.55 \mathrm{eV}, 0.75 \AA), \mathrm{O}_{2}(5.88 \mathrm{eV}, 1.24 \AA), \mathrm{Au}_{2}(2.28 \mathrm{eV}, 2.55 \AA)$ are in a good agreement with experimental data $\mathrm{H}_{2}(4.74 \mathrm{eV}, 0.74 \AA), \mathrm{O}_{2}(5.23 \mathrm{eV}, 1.21 \AA), \mathrm{Au}_{2}(2.29 \mathrm{eV}, 2.47 \AA)[82]$. We also tested the gold-hydrogen interaction by optimizing AuH dimer. The calculated dissociation energy and bond length in $\mathrm{AuH}(3.09 \mathrm{eV}, 1.547 \AA)$ are in a good agreement with experimental data $(3.36 \mathrm{eV}$, $1.524 \AA)[82]$.

\section{Theoretical Results}

\subsection{Adsorption and Activation of $\mathrm{O}_{2}$ on $A u / h-B N$ and $A u_{2} / h-B N$. Role of the Defected $h-B N$ Support}

We start our study with investigation of the catalytic activity of small gold clusters supported on the defected hexagonal BN surface. The h-BN lattice has a layered structure which is very similar to graphite. The planar networks of $\mathrm{B}_{3} \mathrm{~N}_{3}$ hexagons are regularly stacks on top of each other [83]. Due to the partially ionic character of the B-N bonding, the B atoms in one layer are located on top of the $\mathrm{N}$ atoms of the neighboring layer and vice versa, as it is shown in Figure 1(a). Both graphite and h-BN 
materials are strongly bonded within the layers, while interaction between the layers is weak. In spite of similar structures, physical and chemical properties of graphite and h-BN are different. Thus, graphite is an electrical conductor, while h-BN is a dielectric with a wide band gap of 5-6 eV.

Figure 1. h-BN surface models: (a) side view of the two-layer h-BN p $(7 \times 7)$ slab; (b) schematic presentation of the defect-free h-BN surface and h-BN surface with boron $\left(\mathrm{V}_{\mathrm{B}}\right)$ and nitrogen $\left(\mathrm{V}_{\mathrm{N}}\right)$ vacancy defects (only part of the top layer is shown).

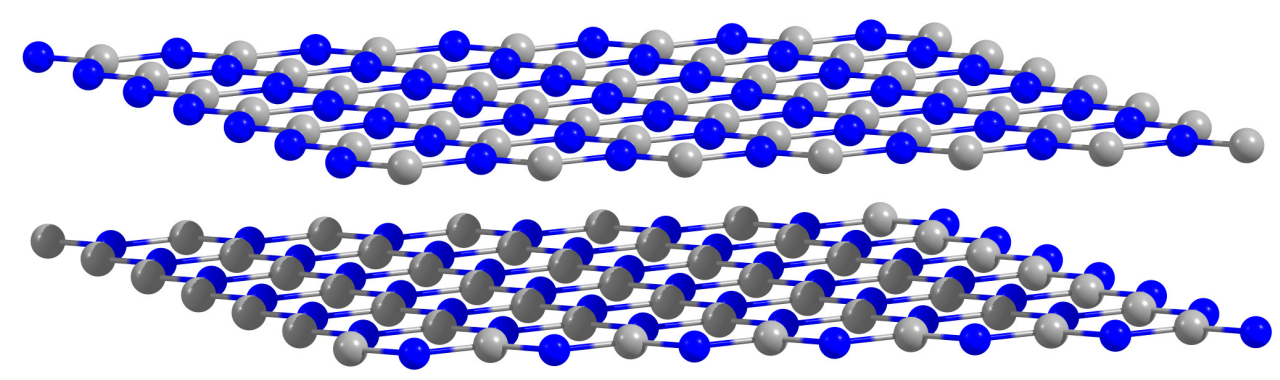

(a)

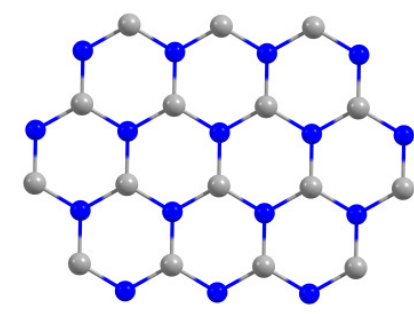

h-BN

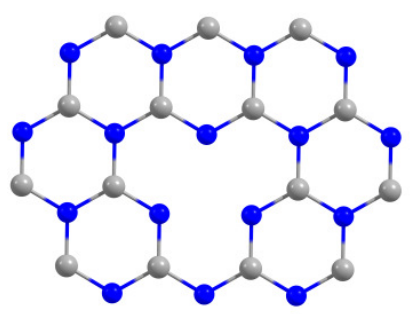

$\mathrm{V}_{\mathrm{B}} @ \mathrm{~h}-\mathrm{BN}$

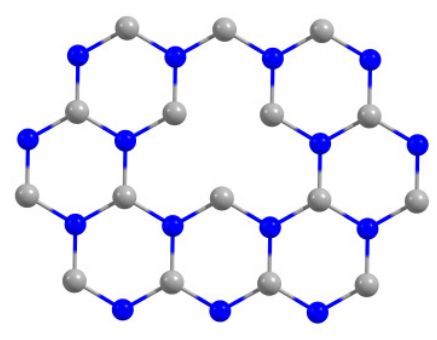

$\mathrm{V}_{\mathrm{N}} @ \mathrm{~h}-\mathrm{BN}$

(b)

In the present work we study adsorption of gold clusters on the h-BN surface with boron $\left(\mathrm{V}_{\mathrm{B}}\right)$ and nitrogen $\left(\mathrm{V}_{\mathrm{N}}\right)$ vacancy defects, which are schematically shown in Figure $1(\mathrm{~b})$. The point $\mathrm{V}_{\mathrm{B}}$ and $\mathrm{V}_{\mathrm{N}}$ defects are the simplest and relatively stable types of defects in h-BN. It was suggested that single boron and nitrogen vacancy defects can exist in h-BN and $V_{N}$ is more stable than $V_{B}[84,85]$. The stability of divacancies in graphitic boron nitride ( $\mathrm{g}-\mathrm{BN})$ sheets has been studied in Reference [86]. It was shown that the divacancies are more frequently formed in graphene than in the g-BN [86]; however, it was demonstrated that in BN single-wall nanotubes the most stable type of point defect is the BN divacancy [87]. Formation of the triangle defects in h-BN monolayer has been also investigated; see, e.g., References $[88,89]$ and references therein. It has been demonstrated that $\mathrm{N}(\mathrm{B})$ triangle defect states of h-BN atomic layer with $\mathrm{N}(\mathrm{B})$ edge atoms have acceptor (donor) levels [89]. A cohesive energy calculation indicates that the $\mathrm{h}-\mathrm{BN}$ atomic layer with $\mathrm{N}$ triangle defects is more or less stable, respectively, than that with $\mathrm{B}$ triangle defects when it is negatively or positively charged [89]. The relative stability of particular type of defects in h-BN often depends on the experimental conditions. Therefore, in the present work we study only the simplest types of single point defects, such as $V_{B}$ and $V_{N}$.

Recently, it was demonstrated that h-BN monolayer binds to surfaces of many $3 \mathrm{~d}$, $4 \mathrm{~d}$, and $5 \mathrm{~d}$ transition metals, forming the so-called nanomesh structure [90]. The interaction between the h-BN monolayer and transition metal support is mainly driven by mixing of $\mathrm{N}-p_{z}$ and $\mathrm{B}-p_{z}$ orbitals of $\mathrm{h}-\mathrm{BN}$ monolayer with the 
$d_{z^{2}}$ transition metal orbitals [91]. Similar effect is responsible for bonding of gold clusters to the h-BN surface. In the case of defect-free h-BN surface, both $\mathrm{Au}$ and $\mathrm{Au}_{2}$ adsorb on top of the $\mathrm{N}$ atom. Our calculations confirm that $\mathrm{Au}$ and $\mathrm{Au}_{2}$ interact weakly with the pristine h-BN surface. Thus, the calculated binding energies of $\mathrm{Au}$ and $\mathrm{Au}_{2}$ on $\mathrm{h}-\mathrm{BN}$ are $E_{b}(\mathrm{Au} / \mathrm{h}-\mathrm{BN})=0.25 \mathrm{eV}$ and $E_{b}\left(\mathrm{Au}_{2} / \mathrm{h}-\mathrm{BN}\right)=0.77 \mathrm{eV}$, respectively. Here, the binding energy of $\mathrm{Au}$ and $\mathrm{Au}_{2}$ to the h-BN surface is defined as

$$
E_{b}\left(\mathrm{Au}_{1,2} / \mathrm{h}-\mathrm{BN}\right)=E_{t o t}\left(\mathrm{Au}_{1,2}\right)+E_{t o t}(\mathrm{~h}-\mathrm{BN})-E_{t o t}\left(\mathrm{Au}_{1,2} / \mathrm{h}-\mathrm{BN}\right)
$$

where $E_{t o t}\left(\mathrm{Au}_{1,2} / \mathrm{h}-\mathrm{BN}\right)$ denotes the total energy of the $\mathrm{Au}_{1,2} / \mathrm{h}-\mathrm{BN}$ system, while $E_{\text {tot }}\left(\mathrm{Au}_{1,2}\right)$ and $E_{t o t}(\mathrm{~h}-\mathrm{BN})$ are the total energies of the non-interacting $\mathrm{Au}$ or $\mathrm{Au}_{2}$ and h-BN slab, respectively. We also found that there is a little charge transfer from the pristine h-BN surface to the adsorbed gold. According to the Bader analysis, the charges localized on the adsorbed $\mathrm{Au}$ and $\mathrm{Au}_{2}$ are -0.08 e and -0.14 e, respectively, where e is an elementary charge.

However, the interaction of $\mathrm{Au}$ and $\mathrm{Au}_{2}$ with the support becomes stronger when the h-BN surface contains $\mathrm{V}_{\mathrm{B}}$ or $\mathrm{V}_{\mathrm{N}}$ point defects. The strong adsorption on vacancy defects is accompanied by the large charge transfer to/from the gold particles. The calculated binding energies of $\mathrm{Au}$ and $\mathrm{Au}_{2}$ to $\mathrm{h}-\mathrm{BN}, \mathrm{V}_{\mathrm{B}}{ }^{\circledR} \mathrm{h}-\mathrm{BN}$ and $\mathrm{V}_{\mathrm{N}}{ }^{\circledR} \mathrm{h}-\mathrm{BN}$ as well as Bader charges localized on the adsorbed gold are summarized in Table 1.

Table 1. Binding energies of $\mathrm{Au}$ and $\mathrm{Au}_{2}$ to the support, and the Bader charges localized on the supported $\mathrm{Au}$ and $\mathrm{Au}_{2}$.

\begin{tabular}{lcccc}
\hline Surface & $E_{b}(A u)(\mathrm{eV})$ & $Q_{A u}(|e|)$ & $E_{b}\left(A u_{2}\right)(\mathrm{eV})$ & $Q_{A u_{2}}(|e|)$ \\
\hline $\mathrm{h}-\mathrm{BN}$ & 0.25 & -0.08 & 0.77 & -0.14 \\
$\mathrm{~V}_{\mathrm{B}}{ }^{\circledR} \mathrm{h}-\mathrm{BN}$ & 3.72 & 0.70 & 3.24 & 0.57 \\
$\mathrm{~V}_{\mathrm{N}}{ }^{\circledR} \mathrm{h}-\mathrm{BN}$ & 3.48 & -0.39 & 3.07 & -0.59 \\
\hline
\end{tabular}

It is important to note that the charge of the adsorbed gold particles strongly depends on the type of vacancy defects, and can possess either negative or positive values. Figures 2 and 3 present the electron density differences $\Delta \rho(r)$ in $\mathrm{Au} / \mathrm{V}_{\mathrm{B}}{ }^{\circledR} \mathrm{h}-\mathrm{BN}$ and $\mathrm{Au} / \mathrm{V}_{\mathrm{N}}{ }^{\circledR} \mathrm{h}-\mathrm{BN}$, respectively. Upper rows in Figures 2 and 3 present the electron density differences $\Delta \rho(r)$ projected on the plane passing through the adsorbed $\mathrm{Au}$ atom; while lower rows demonstrate $\Delta \rho(r)$ projected on the plane passing through three atoms $\mathrm{N}$ (B) atoms in the vicinity the $\mathrm{V}_{\mathrm{B}}\left(\mathrm{V}_{\mathrm{N}}\right)$ vacancy defect on the h-BN surface. Blue and violet regions are electron poor, whereas red and pink are electron rich. It is seen from Figures 2 and 3 that $V_{N}$ donates electrons to the adsorbed $\mathrm{Au}$ and $\mathrm{Au}_{2}$; while $\mathrm{V}_{\mathrm{B}}$ acts as an electron acceptor. Hence, it is possible to modify considerably the cluster's electron donor-acceptor capacity and its catalytic properties via the support design. To demonstrate this effect and to study the specific role played by the defected h-BN support in formation of the catalytic properties of gold we perform systematic investigation of adsorption and activation of $\mathrm{O}_{2}$ on $\mathrm{Au} / \mathrm{h}-\mathrm{BN}$ and $\mathrm{Au}_{2} / \mathrm{h}-\mathrm{BN}$ systems. 
Figure 2. The electron density difference in $\mathrm{Au} / \mathrm{V}_{\mathrm{B}}{ }^{\circledR} \mathrm{h}-\mathrm{BN}$ induced by the interaction of $\mathrm{Au}$ with the boron vacancy $\mathrm{V}_{\mathrm{B}}{ }^{\circledR} \mathrm{h}-\mathrm{BN}$, i.e., $\rho\left(\mathrm{Au} / \mathrm{V}_{\mathrm{B}}{ }^{\circledR} \mathrm{h}-\mathrm{BN}\right)-\rho(\mathrm{Au})-\rho\left(\mathrm{V}_{\mathrm{B}}{ }^{\circledR} \mathrm{h}-\mathrm{BN}\right)$ and projected on the planes parallel to the $\mathrm{h}-\mathrm{BN}$ surface. Plane passing through the adsorbed $\mathrm{Au}$ atom (upper row); plane passing through three $\mathrm{N}$ atoms nearby the boron vacancy $\mathrm{V}_{\mathrm{B}}$ (lower row). Blue and violet regions correspond to the electron loss, whereas red and pink regions correspond to the excess of the electron charge.
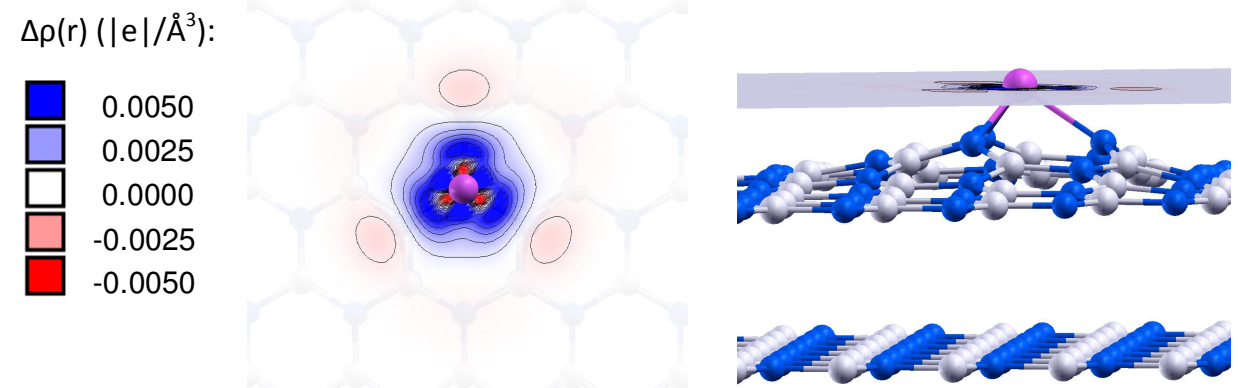

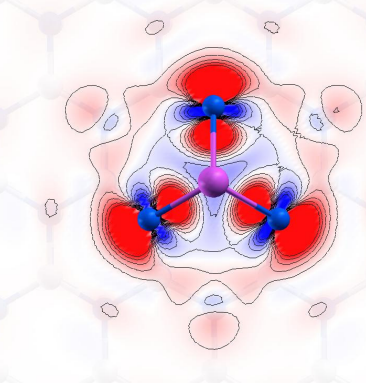

top view

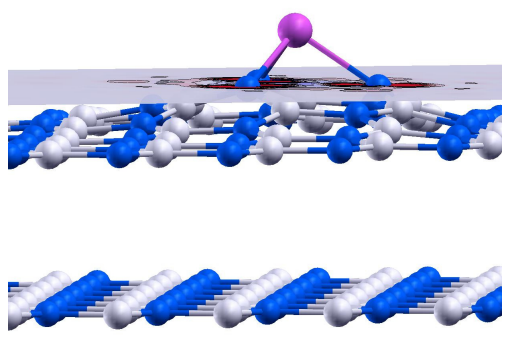

side view

Figure 3. The same as in Figure 2, but for $\mathrm{Au} / \mathrm{V}_{\mathrm{N}}{ }^{\circledR} \mathrm{h}-\mathrm{BN}$.
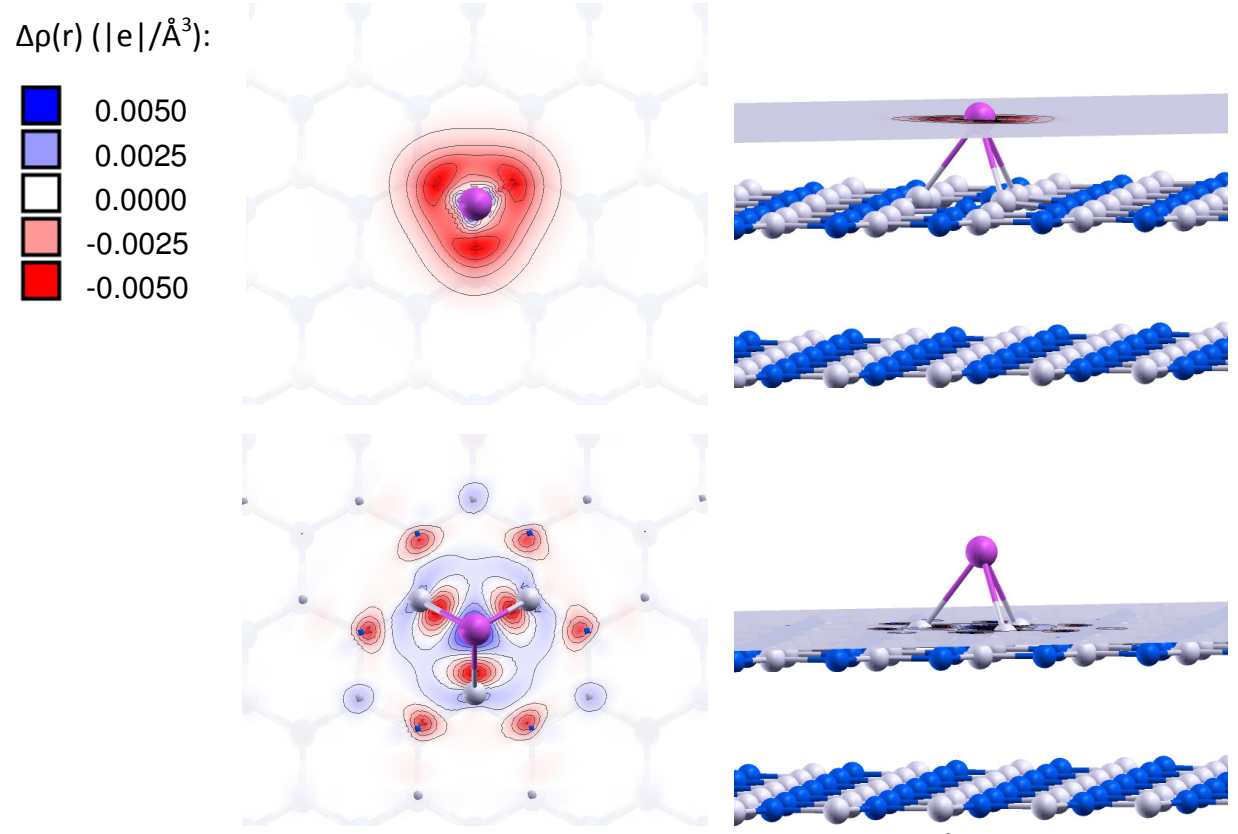

top view

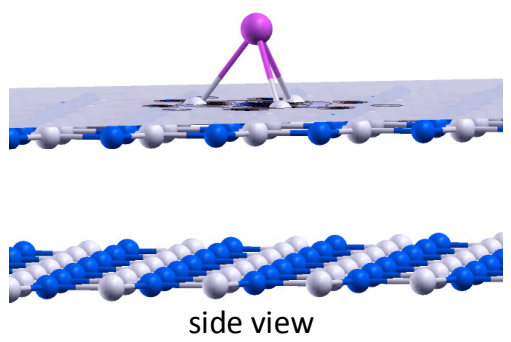


Adsorption of molecular oxygen on free gold clusters has been intensively investigated; see, e.g., References [10,29-31] and references therein. It was found that $\mathrm{O}_{2}$ readily adsorbs and becomes catalytically activated on small neutral gold clusters with an odd number of atoms as well as on gold cluster anions. Such an ability of small gold clusters to bind and activate molecular oxygen has been explained by the transfer of unpaired valence electron from the cluster to the oxygen anti-bonding $2 \pi^{*}$ orbital, see, e.g., References [10,29-31] and references therein. Our calculations demonstrate that $\mathrm{O}_{2}$ adsorbs on the free $\mathrm{Au}$ and $\mathrm{Au}_{2}$ with the binding energy of $0.49 \mathrm{eV}$ and $0.48 \mathrm{eV}$, respectively. The $\mathrm{O}-\mathrm{O}$ bond length enlarges from $1.24 \AA$ (free $\mathrm{O}_{2}$ ) to $1.27 \AA$ and $1.26 \AA$, upon $\mathrm{O}_{2}$ adsorption on gold monomer and dimer, respectively. Slight increase in the $\mathrm{O}-\mathrm{O}$ bond length of the adsorbed $\mathrm{O}_{2}$ demonstrates its catalytic activation.

Can the defected h-BN support modify the catalytic properties of gold? Our calculations demonstrate that $\mathrm{O}_{2}$ readily adsorbs on $\mathrm{Au}$ and $\mathrm{Au}_{2}$ trapped by the defected h-BN surface. Figure 4 presents optimized geometries of $\mathrm{O}_{2}$ adsorbed on the free and supported $\mathrm{Au}$ and $\mathrm{Au}_{2}$. It is seen from Figure 4 that oxygen molecule adsorbs on top of the $\mathrm{Au}$ atom trapped by the $\mathrm{V}_{\mathrm{B}}{ }^{\circledR} \mathrm{h}-\mathrm{BN}$ defect and bridges $\mathrm{Au}$ and $\mathrm{B}$ atoms in the case of adsorption on $\mathrm{Au} / \mathrm{V}_{\mathrm{N}}{ }^{\circledR} \mathrm{h}-\mathrm{BN}$. In the case of the supported gold dimer, $\mathrm{O}_{2}$ bridges two gold atoms on $\mathrm{Au}_{2} / \mathrm{V}_{\mathrm{B}}{ }^{\circledR} \mathrm{h}-\mathrm{BN}$; while for the $\mathrm{Au}_{2} / \mathrm{V}_{\mathrm{N}}{ }^{\circledR} \mathrm{h}-\mathrm{BN}$ system, $\mathrm{O}_{2}$ bridges nearest to the surface $\mathrm{Au}$ atom, which is located on top of $\mathrm{V}_{\mathrm{N}}$ and $\mathrm{B}$ atom on the surface. Therefore an interface between the supported gold cluster and the h-BN surface might play an important role in oxidation reactions on the supported gold clusters.

Figure 4. Optimized geometries of $\mathrm{O}_{2}$ adsorbed on the free and supported $\mathrm{Au}$ and $\mathrm{Au}_{2}$. The interatomic distances are given in Angstroms. Only part of the h-BN slab is shown.

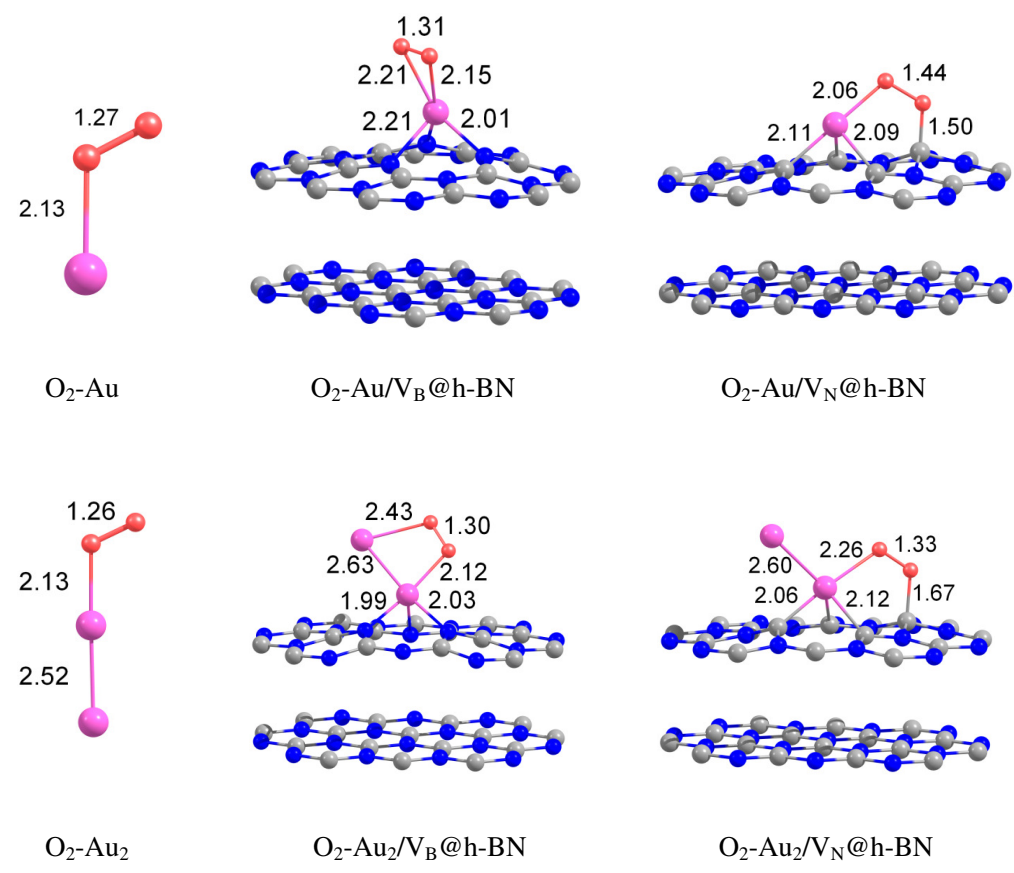

Interaction of $\mathrm{Au}$ and $\mathrm{Au}_{2}$ with the support results in additional activation of the adsorbed $\mathrm{O}_{2}$ and weakening of the $\mathrm{O}-\mathrm{O}$ bond. This effect is especially strong for $\mathrm{V}_{\mathrm{N}}$ vacancy defect, which acts as an electron donor for the supported $\mathrm{Au}$ and $\mathrm{Au}_{2}$. Figure 4 demonstrates that the $\mathrm{O}-\mathrm{O}$ bond length in adsorbed $\mathrm{O}_{2}$ is enlarged similar to superoxide and peroxide states (the $\mathrm{O}-\mathrm{O}$ bond distances in $\mathrm{O}_{2}^{-}$ 
and $\mathrm{O}_{2}^{2-}$ are $1.33 \AA$ and $1.49 \AA$ [92], respectively). The results of our calculations demonstrate that interaction of $\mathrm{Au}$ and $\mathrm{Au}_{2}$ with the defected h-BN surface can lead to a dramatic change in the catalytic activity of gold.

Table 2. Binding energies of $\mathrm{O}_{2}$ to free and supported $\mathrm{Au}$ and $\mathrm{Au}_{2}$; the $\mathrm{O}-\mathrm{O}$ bond length, $d_{\mathrm{O}-\mathrm{O}}$, and the Bader charges localized on $\mathrm{Au}_{1,2}, \mathrm{O}_{2}$ and $\mathrm{O}_{2}-\mathrm{Au}_{1,2}$ calculated for free and supported $\mathrm{Au}$ and $\mathrm{Au}_{2}$ with the adsorbed $\mathrm{O}_{2}$.

\begin{tabular}{lccccc}
\hline Surface & $E_{b}\left(\mathbf{O}_{2}\right)(\mathbf{e V})$ & $d_{O-O}(\AA)$ & $Q_{A u_{1,2}}(|e|)$ & $Q_{\mathrm{O}_{2}}(|e|)$ & $Q_{O_{2}-A u_{1,2}}(|e|)$ \\
\hline $\mathrm{Au}$ & 0.49 & 1.27 & 0.19 & -0.19 & 0.00 \\
$\mathrm{Au} / \mathrm{V}_{\mathrm{B}}{ }^{\circledR} \mathrm{h}-\mathrm{BN}$ & 0.90 & 1.31 & 0.98 & -0.33 & 0.66 \\
$\mathrm{Au} / \mathrm{V}_{\mathrm{N}}{ }^{\circledR} \mathrm{h}-\mathrm{BN}$ & 1.10 & 1.44 & -0.10 & -1.31 & -1.41 \\
$\mathrm{Au}$ & 0.48 & 1.26 & 0.15 & -0.15 & 0.00 \\
\hline
\end{tabular}

Table 2 presents the binding energies of $\mathrm{O}_{2}, E_{b}\left(\mathrm{O}_{2}\right)$, to the free and h-BN supported $\mathrm{Au}$ and $\mathrm{Au}_{2}$. Interaction of $\mathrm{Au}$ and $\mathrm{Au}_{2}$ with the $\mathrm{h}-\mathrm{BN}$ support results in the considerable change in oxygen binding. Thus, $\mathrm{O}_{2}$ adsorbs on $\mathrm{Au} / \mathrm{V}_{\mathrm{B}}{ }^{\circledR} \mathrm{h}-\mathrm{BN}$ and $\mathrm{Au} / \mathrm{V}_{\mathrm{N}}{ }^{\circledR} \mathrm{h}-\mathrm{BN}$ with binding energies of $0.90 \mathrm{eV}$ and $1.10 \mathrm{eV}$, respectively. This is twice larger than the binding energy of $\mathrm{O}_{2}$ to the free Au. The strong change in binding of $\mathrm{O}_{2}$ to $\mathrm{Au} / \mathrm{V}_{\mathrm{B}}{ }^{\circledR} \mathrm{h}-\mathrm{BN}$ and $\mathrm{Au} / \mathrm{V}_{\mathrm{N}}{ }^{\circledR} \mathrm{h}-\mathrm{BN}$ can be explained by the large charge transfer between the corresponding point defects and the trapped Au atom. It is interesting that binding of $\mathrm{O}_{2}$ to $\mathrm{Au}_{2} / \mathrm{V}_{\mathrm{B}}{ }^{\circledR} \mathrm{h}-\mathrm{BN}$ center is weaker if compared with free $\mathrm{Au}_{2}$. However, adsorption of $\mathrm{O}_{2}$ on $\mathrm{Au}_{2} / \mathrm{V}_{\mathrm{N}}{ }^{\circledR} \mathrm{h}-\mathrm{BN}$ is highly promoted. In the latter case $\mathrm{O}_{2}$ bridges one of the gold atoms and the nearest boron atom on the surface, with binding energy of $1.30 \mathrm{eV}$. Thus, the oxygen binding to the supported gold particles considerably depends on the number of gold atoms and the type of the support. Activation and reactivity of the adsorbed $\mathrm{O}_{2}$ are strongly affected by the charge transfer from the gold hybridized 5d6s orbitals to the anti-bonding $2 \pi^{*}$ orbital of $\mathrm{O}_{2}$. In the case of $\mathrm{O}_{2}$ adsorption on free $\mathrm{Au}$, the Bader charge localized on $\mathrm{O}_{2}$ is -0.19 e. The charge transfer from $\mathrm{Au}$ to $\mathrm{O}_{2}$ is responsible for the catalytic activation of the adsorbed $\mathrm{O}_{2}$ and weakening of the $\mathrm{O}-\mathrm{O}$ bond. Interaction of $\mathrm{Au}$ with the defected h-BN support results in the drastic increase in charge transfer to the adsorbed $\mathrm{O}_{2}$. That means that the interaction of $\mathrm{Au}$ and $\mathrm{Au}_{2}$ with the defected h-BN support considerably promotes the charge transfer from the gold to $\mathrm{O}_{2}$. Such an effect becomes very clear for $\mathrm{O}_{2}$ adsorbed on the $\mathrm{Au} / \mathrm{V}_{\mathrm{B}}{ }^{\circledR} \mathrm{h}-\mathrm{BN}$ center. As we have discussed above, the $\mathrm{B}$ vacancy acts as an electron acceptor. Thus, Au trapped by the $\mathrm{V}_{\mathrm{B}}{ }^{\circledR} \mathrm{h}-\mathrm{BN}$ defect possesses a positive charge. It is well known that free gold cluster cations are inert toward molecular oxygen. However, our calculations demonstrate that $\mathrm{O}_{2}$ readily adsorbs and becomes highly activated on the positively charged $\mathrm{Au} / \mathrm{V}_{\mathrm{B}}{ }^{\circledR} \mathrm{h}-\mathrm{BN}$ center. Interaction with the $\mathrm{V}_{\mathrm{B}}{ }^{\circledR} \mathrm{h}-\mathrm{BN}$ support promotes additional charge transfer (in comparison with $\mathrm{O}_{2}$ adsorbed on free $\mathrm{Au}$ ) from the gold to the adsorbed $\mathrm{O}_{2}$, even if the adsorbed $\mathrm{Au}$ has a positive charge. This effect is rather similar to that of promotion of oxygen activation by the small gold clusters with coadsorbed hydrogen [27] or ethylene [11] molecules. In the case of $\mathrm{O}_{2}$ adsorption on the $\mathrm{Au} / \mathrm{V}_{\mathrm{N}}{ }^{\circledR} \mathrm{h}-\mathrm{BN}$ center, gold atom trapped by the $\mathrm{N}$ vacancy has a negative charge. That promotes charge transfer to the adsorbed $\mathrm{O}_{2}$. However, in contrast to the case of the $\mathrm{Au} / \mathrm{V}_{\mathrm{B}}{ }^{\circledR} \mathrm{h}-\mathrm{BN}$ adsorption 
center, the additional charge transfer to the oxygen adsorbed on $\mathrm{Au} / \mathrm{V}_{\mathrm{N}}{ }^{\circledR} \mathrm{h}-\mathrm{BN}$ occurs mainly due to the charge transfer from the support.

It is seen from Table 2 that adsorption of $\mathrm{O}_{2}$ on $\mathrm{Au}_{2} / \mathrm{V}_{\mathrm{B}}{ }^{\circledR} \mathrm{h}-\mathrm{BN}$ is accompanied by the additional charge transfer from $\mathrm{Au}_{2}$, while the total charge transfer from the $\mathrm{V}_{\mathrm{B}}{ }^{\circledR} \mathrm{h}-\mathrm{BN}$ support to the $\mathrm{Au}_{2}$ and $\mathrm{O}_{2}-\mathrm{Au}_{2}$ adsorbates remains unchanged. Hence, interaction of $\mathrm{Au}_{2}$ with the $\mathrm{V}_{\mathrm{B}}{ }^{\circledR} \mathrm{h}-\mathrm{BN}$ defect promotes charge transfer from the gold to the oxygen. However, in the case of $\mathrm{O}_{2}$ adsorption on $\mathrm{Au}_{2} / \mathrm{V}_{\mathrm{N}}{ }^{\circledR} \mathrm{h}-\mathrm{BN}$ center an additional charge transfer to $\mathrm{O}_{2}$ occurs mainly due to the charge transfer from the $\mathrm{V}_{\mathrm{N}}{ }^{\circledR} \mathrm{h}$-BN center, but not from the gold dimer. In both cases charge transfer to $\mathrm{O}_{2}$ is accompanied by its strong activation.

Thus, we found that strong adsorption of $\mathrm{Au}$ and $\mathrm{Au}_{2}$ on the surface defects is accompanied by the charge transfer to/from the adsorbate. The value and the sign of the charge accumulated on the adsorbate depend on the adsorption sites. Thus, $\mathrm{V}_{\mathrm{N}}$ donates electrons to the adsorbed $\mathrm{Au}$ and $\mathrm{Au}_{2} ;$ while $\mathrm{V}_{\mathrm{B}}$ acts as an electron acceptor. The excess of the positive or negative charge on the supported gold clusters can considerably promote their catalytic properties and enhance activation of the adsorbed $\mathrm{O}_{2}$.

\subsection{Adsorption and Dissociation of $\mathrm{H}_{2}$ on $\mathrm{Au}_{n} / \mathrm{TiO}_{2}$ (110). Interface Effects}

Let us consider catalytic activity of gold clusters supported on the active surface of rutile $\mathrm{TiO}_{2}(110)$. The $\mathrm{TiO}_{2}(110)$ surface contains oxygen and titanium atoms with different coordination. The fivefold coordinated $\mathrm{Ti}$ atoms are undercoordinated relatively to the bulk sixfold coordinated $\mathrm{Ti}$, as it is shown in Figure 5. The $\mathrm{O}$ atoms raised above the plane of $\mathrm{Ti}$ atoms are twofold coordinated. These atoms are called bridge-site $\mathrm{O}$. The oxygen atoms lying in the plane of $\mathrm{Ti}$ atoms are threefold coordinated. Relaxation of the $\mathrm{TiO}_{2}(110)$ surface results in a surface rumpling, as it is shown in Figure 5. The undercoordinated $\mathrm{Ti}$ and $\mathrm{O}$ atoms are moving inward by $0.10 \AA$, decreasing the distance with subsurface atoms. The sixfold coordinated $\mathrm{Ti}$ atoms and threefold coordinated $\mathrm{O}$ atoms are moving outward by $0.1 \AA$ and $0.2 \AA$, respectively. The similar puckered structure of the rutile (110) surface has been reported in References [93,94].

Figure 5. Side view of the $\mathrm{TiO}_{2}(110) \mathrm{p}(2 \times 5)$ slab. The bridge-site twofold coordinated $\mathrm{O}(2)$ atom, threefold coordinated $\mathrm{O}(3)$ atom, five- and six-fold coordinated $\mathrm{Ti}(5)$ and $\mathrm{Ti}(6)$ atoms are marked, respectively. Relaxation of the $\mathrm{TiO}_{2}(110)$ surface results in a surface rumpling.

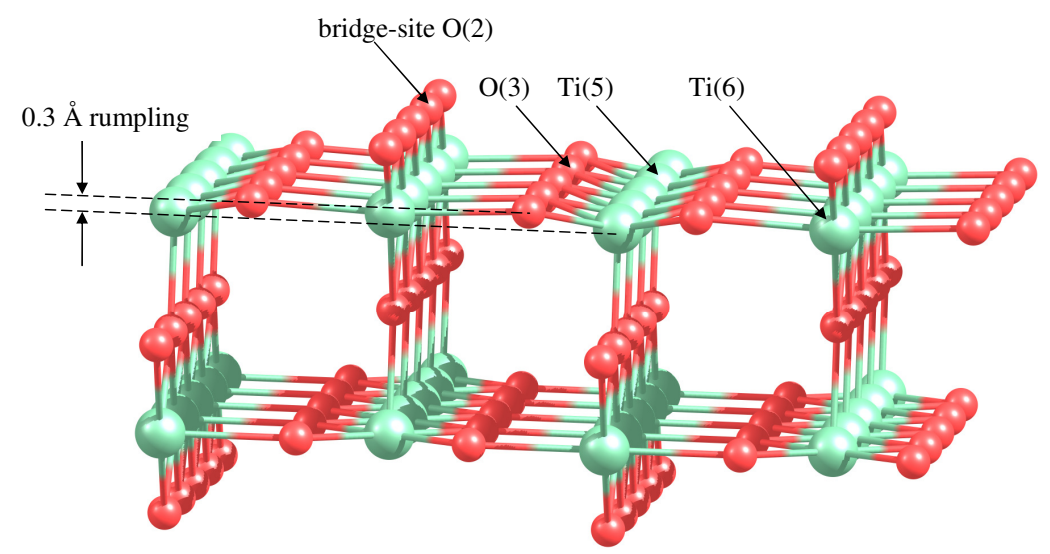


Our calculations demonstrate that $\mathrm{H}_{2}$ can be adsorbed on the pure, defect-free $\operatorname{TiO}_{2}(110)$ surface, even in the absence of the gold particle. The most stable geometries calculated for the molecular and dissociative adsorption of $\mathrm{H}_{2}$ on the pure rutile $\mathrm{TiO}_{2}(110)$ surface are presented in Figure 6. It is seen that $\mathrm{H}_{2}$ preferably adsorbs on top of the Ti(5) atom with the binding energy of $0.14 \mathrm{eV}$. The $\mathrm{H}-\mathrm{H}$ bond length of $0.78 \AA$ is slightly increased in comparison with the free $\mathrm{H}_{2}$. The dissociative state of $\mathrm{H}_{2}$ on $\mathrm{TiO}_{2}(110)$ corresponds to the situation when both $\mathrm{H}$ atoms form the $\mathrm{OH}$ group with the low coordinated $\mathrm{O}(2)$ bridge atoms on the rutile surface. The binding energy of the dissociated configuration of $\mathrm{H}_{2}$ is $1.50 \mathrm{eV}$; however, the distance between two rows of $\mathrm{O}(2)$ atoms on $\mathrm{TiO}_{2}(110)$ is $6.50 \AA$, which is too large to promote dissociation of the $\mathrm{H}_{2}$ adsorbed on top of Ti(5) atom. In this case $\mathrm{H}_{2}$ would dissociate in the vicinity of the adsorption center as a first step, followed by adsorption of $\mathrm{H}$ atoms on $\mathrm{O}(2)$. This process requires to overcome a dissociation barrier of $\sim 4.3 \mathrm{eV}$ which is much higher than the energy of the molecular adsorption. In this situation $\mathrm{H}_{2}$ would desorb from the surface and fly away rather than dissociate. Therefore, to promote $\mathrm{H}_{2}$ dissociation on $\mathrm{TiO}_{2}(110)$, it is necessary to have adsorption centers on the rutile surface in the vicinity of low coordinated $\mathrm{O}(2)$ atoms. Supported gold clusters can serve as a source of such centers.

Figure 6. Optimized geometries for molecular (left) and dissociative (right) adsorption of $\mathrm{H}_{2}$ on the pure rutile $\mathrm{TiO}_{2}(110)$ surface.
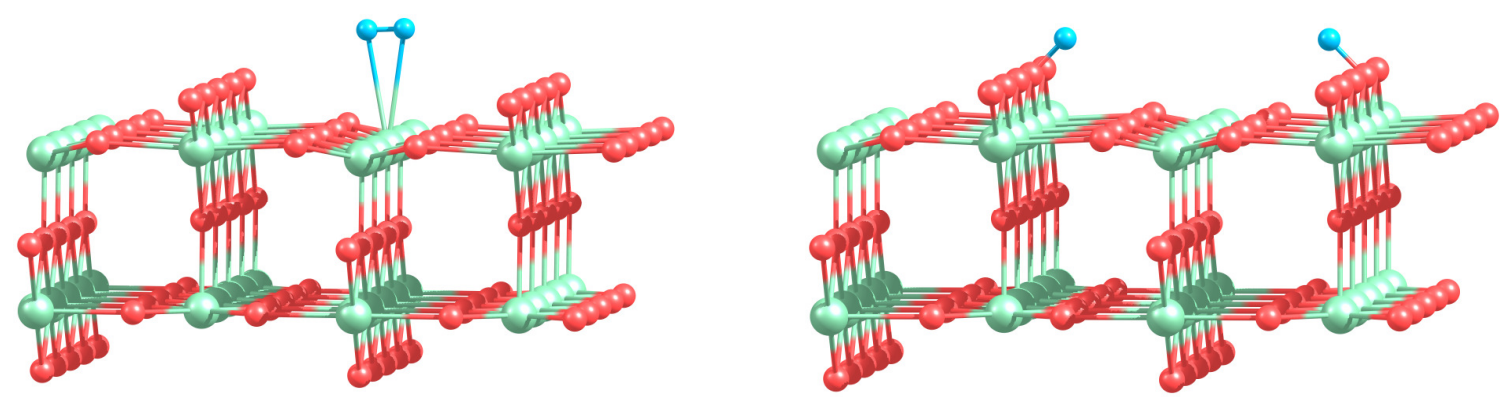

In the present work we consider adsorption of $\mathrm{H}_{2}$ on the most stable isomers of free and supported gold clusters $\mathrm{Au}_{n}$ consisting of $n=1,2,8$ and 20 atoms. Figure 7 presents the optimized geometries of $\mathrm{H}_{2}-\mathrm{Au}_{n}$ systems in the case of molecular and dissociative adsorption of $\mathrm{H}_{2}$ on free $\mathrm{Au}_{n}$ clusters. In order to obtain the most stable configuration of $\mathrm{H}_{2}$ adsorbed on $\mathrm{Au}_{n}$, we have created a large number of starting geometries by adding $\mathrm{H}_{2}$ molecule in different positions (up to 30) on the surface of the considered clusters. The starting structures have been optimized further without any geometric constraints. We have successfully used a similar approach to find the optimized geometries of $\mathrm{O}_{2}$ and $\mathrm{C}_{2} \mathrm{H}_{4}$ molecules adsorbed on small neutral, anionic and cationic gold clusters [10,11,37,95]. The binding energies for molecular, $E_{b}^{m o l}$, and dissociative, $E_{b}^{\text {dis }}$, adsorption of $\mathrm{H}_{2}$ on free $\mathrm{Au}_{n}$ as well as the $\mathrm{H}-\mathrm{H}$ bond length $r_{H-H}^{m o l}$ in $\mathrm{H}_{2}$ adsorbed molecularly are summarized in Table 3.

Results of our calculations demonstrate that $\mathrm{H}_{2}$ binds weakly to $\mathrm{Au}$ as a molecule, with $E_{b}^{m o l}=0.13 \mathrm{eV}$. Dissociation of $\mathrm{H}_{2}$ on $\mathrm{Au}$ is not favorable energetically. The $\mathrm{H}-\mathrm{H}$ bond length in $\mathrm{H}_{2}$ adsorbed on $\mathrm{Au}$ is slightly enlarged in comparison with the free $\mathrm{H}_{2}$. Adsorption of $\mathrm{H}_{2}$ on $\mathrm{Au}_{2}$ is relatively strong, with the binding energy equal to $0.59 \mathrm{eV}$ both for the molecular and the dissociative adsorption. Table 3 demonstrates that the $\mathrm{H}-\mathrm{H}$ bond length increases to $0.845 \AA$ in $\mathrm{H}_{2}-\mathrm{Au}_{2}$, indicating 
that $\mathrm{H}_{2}$ is highly activated. With the further increase in cluster size the binding energy calculated for molecular adsorption of $\mathrm{H}_{2}$ decreases to $0.26 \mathrm{eV}$ for $\mathrm{Au}_{8}$ and $0.09 \mathrm{eV}$ both for $\mathrm{Au}_{20}$. On the other hand, the dissociative adsorption of $\mathrm{H}_{2}$ becomes energetically favorable both for $\mathrm{Au}_{8}$ and $\mathrm{Au}_{20}$.

Figure 7. Optimized geometries of $\mathrm{H}_{2}-\mathrm{Au}_{n}$ clusters in the case of molecular (left) and dissociative (right) adsorption of $\mathrm{H}_{2}$.

\section{$\mathrm{Au}$}
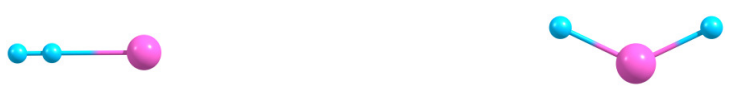

$\mathrm{Au}_{2}$
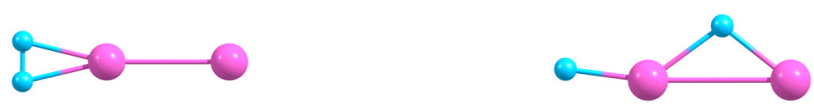

$\mathrm{Au}_{8}$
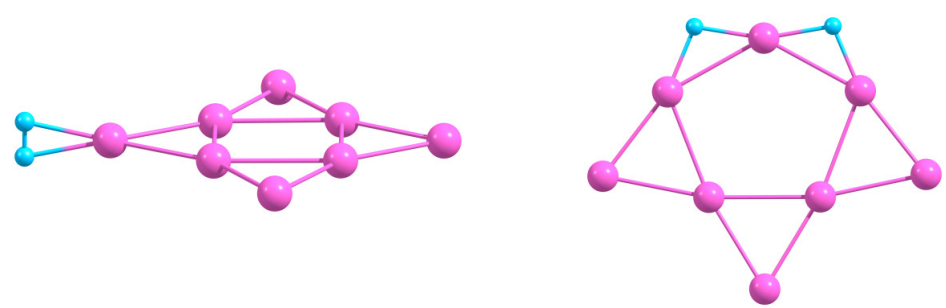

$\mathrm{Au}_{20}$
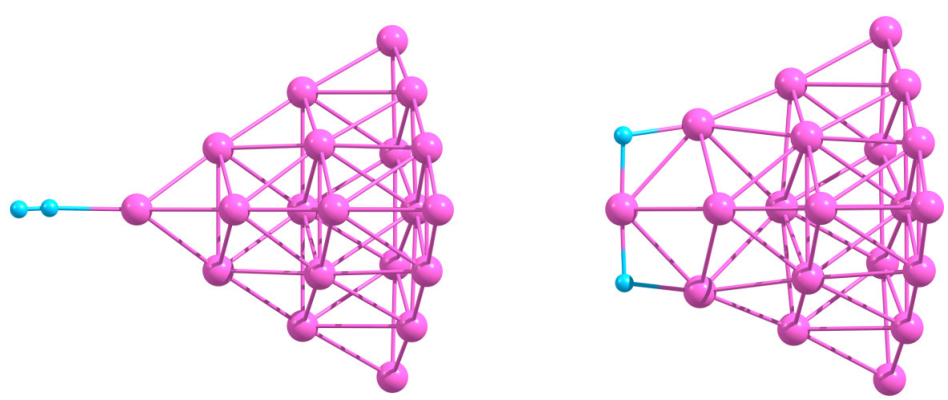

Table 3. Binding energies for molecular, $E_{b}^{\text {mol }}$, and dissociative, $E_{b}^{\text {dis }}$, adsorption of $\mathrm{H}_{2}$ on the most stable free $\mathrm{Au}_{n}$ clusters and the $\mathrm{H}-\mathrm{H}$ bond length, $r_{\mathrm{H}-\mathrm{H}}^{\text {mol }}$, in the case of molecular adsorption of $\mathrm{H}_{2}$.

\begin{tabular}{lccc}
\hline Cluster & $r_{\mathbf{H}-\mathbf{H}}^{\text {mol }}(\mathbf{\AA})$ & $E_{b}^{\text {mol }}(\mathbf{e V})$ & $E_{b}^{\text {dis }}(\mathbf{e V})$ \\
\hline $\mathrm{Au}$ & 0.780 & 0.13 & 0.04 \\
$\mathrm{Au}_{2}$ & 0.845 & 0.59 & 0.59 \\
$\mathrm{Au}_{8}$ & 0.806 & 0.26 & 0.68 \\
$\mathrm{Au}_{20}$ & 0.768 & 0.09 & 0.14 \\
\hline
\end{tabular}

One of the factors that influence $\mathrm{H}_{2}$ dissociation is coordination of Au atoms interacting with hydrogen and flexibility of cluster structure, as was discussed in [96]. It is seen from Figure 7 that $\mathrm{H}_{2}$ dissociates at the low coordinated corner Au atom with formation of the slightly bent $\mathrm{H}-\mathrm{Au}-\mathrm{H}$ bond. 
Note, that the $\mathrm{Au}-\mathrm{Au}$ bond length in $\mathrm{Au}_{2}$ does not change noticeably upon molecular adsorption of $\mathrm{H}_{2}$; but increases up to $2.753 \AA$ for dissociative adsorption. In the case of $\mathrm{Au}_{8}$ and $\mathrm{Au}_{20}$ dissociation of $\mathrm{H}_{2}$ on the cluster surface is accompanied by the structural (at least local) transformations, although $\mathrm{Au}_{20}$ demonstrates rather strong structural stability, due to the "magic" nature of this cluster.

How does the interaction with the support influence the reactivity of gold clusters? In the present work we perform a systematic theoretical study of the structure and energetics of $\mathrm{H}_{2}$ adsorbed on $\mathrm{Au}_{1}$, $\mathrm{Au}_{2}, \mathrm{Au}_{8} \mathrm{Au}_{20}$ clusters supported on the rutile $\mathrm{TiO}_{2}(110)$ surface. The analysis of the energetics of $\mathrm{H}_{2}$ adsorption on the supported gold clusters provides deep insights into the nature of bonding and dissociation of the $\mathrm{H}_{2}$ molecule and reveals the details of the reaction mechanism. Figure 8 shows the most stable geometries of $\mathrm{H}_{2}$ adsorbed on the supported gold clusters. The binding energies calculated for molecular, $E_{b}^{m o l}$, and dissociative, $E_{b}^{d i s}$, adsorption of $\mathrm{H}_{2}$ on $\mathrm{Au}_{n} / \mathrm{TiO}_{2}$, and the $\mathrm{H}-\mathrm{H}$ bond length, $r_{\mathrm{H}-\mathrm{H}}^{m o l}$, in the case of molecular adsorption of $\mathrm{H}_{2}$ are summarized in Table 4.

Figure 8. The most stable geometries of $\mathrm{H}_{2}$ adsorbed on $\mathrm{Au}_{n} / \mathrm{TiO}_{2}$ clusters in the case of molecular (left) and dissociative (right) adsorption of $\mathrm{H}_{2}$.

$\mathrm{Au}$
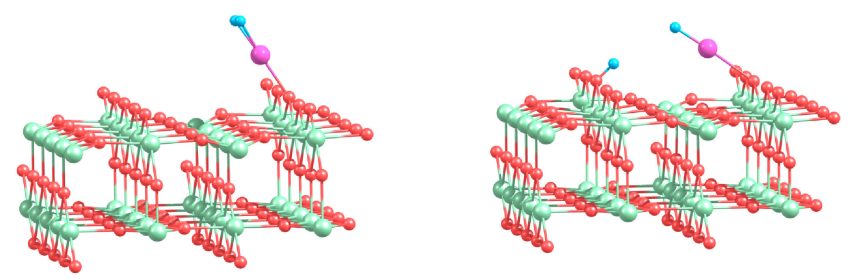

$\mathrm{Au}_{2}$
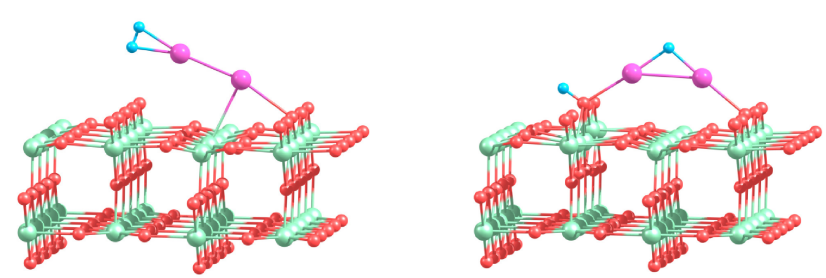

$\mathrm{Au}_{8}$
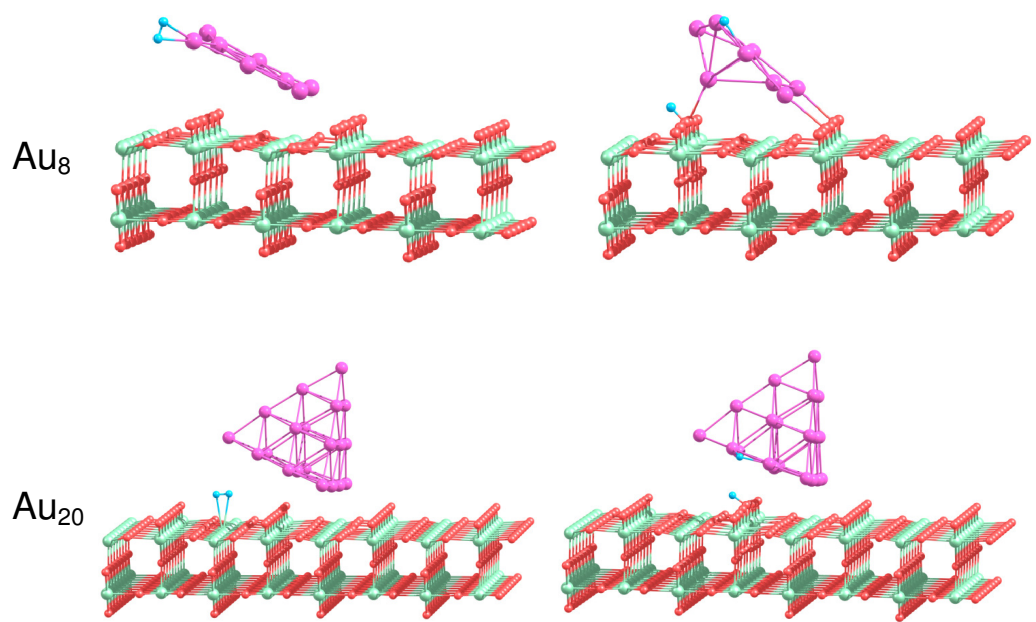
Table 4. Binding energy calculated for molecular, $E_{b}^{\text {mol }}$, and dissociative, $E_{b}^{\text {dis }}$, adsorption of $\mathrm{H}_{2}$ on $\mathrm{Au}_{n} / \mathrm{TiO}_{2}$, and the $\mathrm{H}-\mathrm{H}$ bond length, $r_{\mathrm{H}-\mathrm{H}}^{m o l}$, in the case of molecular adsorption of $\mathrm{H}_{2}$.

\begin{tabular}{lccc}
\hline Cluster & $r_{\mathbf{H}-\mathbf{H}}^{\text {mol }}(\AA)$ & $E_{\boldsymbol{b}}^{\text {mol }}(\mathbf{e V})$ & $E_{\boldsymbol{b}}^{\text {dis }}(\mathbf{e V})$ \\
\hline $\mathrm{Au} / \mathrm{TiO}_{2}$ & 0.906 & 1.15 & 2.06 \\
$\mathrm{Au}_{2} / \mathrm{TiO}_{2}$ & 0.821 & 0.37 & 1.55 \\
$\mathrm{Au}_{8} / \mathrm{TiO}_{2}$ & 0.792 & 0.24 & 1.55 \\
$\mathrm{Au}_{20} / \mathrm{TiO}_{2}$ & 0.795 & 0.17 & 0.83 \\
\hline
\end{tabular}

It is seen from Table 4 that $\mathrm{H}_{2}$ adsorbs molecularly on $\mathrm{Au} / \mathrm{TiO}_{2}$ with a binding energy of $1.15 \mathrm{eV}$, which is considerably larger than the corresponding energy calculated for $\mathrm{H}_{2}$ adsorbed on free $\mathrm{Au}$ atom. The adsorbed $\mathrm{H}_{2}$ is highly activated, with the $\mathrm{H}-\mathrm{H}$ bond length $r_{\mathrm{H}-\mathrm{H}}^{m o l}=0.906 \AA$. As a result of $\mathrm{H}_{2}$ adsorption, the supported $\mathrm{Au}$ atom shifts slightly towards the row of the low coordinated $\mathrm{O}(2)$ bridge atoms. In the previous section we demonstrated that $\mathrm{H}_{2}$ dissociation is not favorable on the free $\mathrm{Au}$ atom. However, in the case of the supported $\mathrm{Au}$ atom, dissociation of $\mathrm{H}_{2}$ can occur with formation of the $\mathrm{OH}$ group with the $\mathrm{O}(2)$ atom located either in the nearest to Au row of $\mathrm{O}(2)$ or in the next row of $\mathrm{O}(2)$, as is shown in Figure 8. In the latter case the calculated binding energy $E_{b}^{d i s}=2.06 \mathrm{eV}$ is higher, not only if compared with the binding energy for molecular adsorption of $\mathrm{H}_{2}$ on $\mathrm{Au} / \mathrm{TiO}_{2}(110)$, but also if compared with the binding energy of the dissociated state of $\mathrm{H}_{2}$ on the pure $\mathrm{TiO}_{2}(110)$ surface. Thus, we can conclude, from the energetic point of view, that the $\mathrm{TiO}_{2}(110)$ support considerably promotes $\mathrm{H}_{2}$ dissociation on $\mathrm{Au}$ atom.

We found that molecular $\mathrm{H}_{2}$ binds to the supported $\mathrm{Au}_{2}$ in a similar way as for the free $\mathrm{Au}_{2}$. However, the binding energy calculated for the molecular adsorption of $\mathrm{H}_{2}$ on $\mathrm{Au}_{2} / \mathrm{TiO}_{2}$ is lower than the corresponding energy obtained for free $\mathrm{Au}_{2}$. The dissociated hydrogen atom can migrate to the row of $\mathrm{O}(3)$ atoms, or to the row of $\mathrm{O}(2)$ bridge atoms on the rutile surface, forming $\mathrm{OH}$ bonds. The interaction of $\mathrm{Au}_{2}$ with the support results in the energetic promotion of $\mathrm{H}_{2}$ dissociation on the supported $\mathrm{Au}_{2}$.

The optimized geometries of $\mathrm{H}_{2}$ in the case of its molecular adsorption on the supported $\mathrm{Au}_{8}$ cluster similar to those obtained for the corresponding free $\mathrm{Au}_{8}$. However, the dissociative adsorption of $\mathrm{H}_{2}$ on $\mathrm{Au}_{8}$ results in the considerable rearrangement of the cluster structure. The dissociative configuration of $\mathrm{H}_{2}$ on the supported $\mathrm{Au}_{8}$ is promoted energetically. Migration of $\mathrm{H}$ on the low coordinated $\mathrm{O}(2)$ atom results in formation of the $\mathrm{OH}$ bond and considerable increase in binding energies calculated for $\mathrm{H}_{2}$ adsorbed dissociatively.

The $\mathrm{Au}_{20}$ clusters supported on $\mathrm{TiO}_{2}(110)$ are the largest systems studied in the present work. It was shown above that the hydrogen molecule binds weakly to the free $\mathrm{Au}_{20}$ clusters. We have found that, in the case of the supported $\mathrm{Au}_{20}$, the hydrogen molecule adsorbs on top of the Ti(5) atoms on the rutile surface in the vicinity of $\mathrm{Au}_{20}$, rather than directly on the $\mathrm{Au}_{20}$ clusters. After $\mathrm{H}_{2}$ dissociation in the vicinity of $\mathrm{Au}_{20} / \mathrm{TiO}_{2}$ one of the $\mathrm{H}$ atoms binds to the edge of $\mathrm{Au}_{20}$ that are oriented perpendicularly to the rows of $\mathrm{O}(2)$ surface atoms, while another $\mathrm{H}$ forms the $\mathrm{OH}$ bond with the $\mathrm{O}(2)$ atom on the rutile surface. However, this configuration is not stable in comparison with the situation when both of $\mathrm{H}$ atoms 
form $\mathrm{OH}$ surface group. Therefore, $\mathrm{H}$ atom on the edge of the supported $\mathrm{Au}_{20}$ cluster will further migrate towards the low coordinated $\mathrm{O}(2)$ atoms on the rutile surface.

Our calculations demonstrate that combination (interplay) of several factors such as geometric structure, presence of the low coordinated oxygen atoms in the vicinity of the cluster-surface interface, etc., are important for $\mathrm{H}_{2}$ dissociation. What is the role of the charge transfer from the gold cluster to hydrogen in $\mathrm{H}_{2}$ dissociation? As it was discussed in previous section, the charge transfer from the gold to the antibonding orbital of $\mathrm{O}_{2}$ is responsible for the catalytic activation of $\mathrm{O}_{2}$. However, in the case of $\mathrm{H}_{2}$ dissociation the analysis of the Bader charges [79,80] demonstrate that there is no considerable charge transfer between the adsorbed hydrogen and the gold clusters (free or supported). Thus, the largest charge transfer occurs for $\mathrm{H}_{2}$ adsorbed molecularly on $\mathrm{Au} / \mathrm{TiO}_{2}$. In this case the calculated Bader charge localized on $\mathrm{H}_{2}$ is $+0.11 \mathrm{e}$, where e is the elementary charge. Although such a charge transfer is relatively small, it might be responsible for the strong enlargement of the $\mathrm{H}-\mathrm{H}$ bond length in $\mathrm{H}_{2}-\mathrm{Au} / \mathrm{TiO}_{2}$ up to $0.906 \AA$. In most cases of molecular adsorption of hydrogen, the adsorbed molecule possesses some small positive charge. However, after dissociation, the hydrogen atoms can get an excess of negative charge. Depending on the geometric configuration, either both of the hydrogen atoms possess some small negative charge, or one $\mathrm{H}$ is charged negatively, while another $\mathrm{H}$ is charged positively. Thus, for example the $\mathrm{H}-\mathrm{H}$ bond cleavage on the unsupported $\mathrm{Au}_{2}$ can be considered as heterolytic-one $\mathrm{H}$ possesses negative charge of $-0.11 \mathrm{e}$, while another $\mathrm{H}$ possesses very small positive charge of $+0.01 \mathrm{e}$. In this case the gold dimer becomes positively charged upon $\mathrm{H}_{2}$ dissociation with the net charge of +0.1 e. On the other hand, formation of the $\mathrm{OH}$ group with the bridge $\mathrm{O}(2)$ atom on the rutile surface is accompanied by the large charge transfer from $\mathrm{H}$ atom to $\mathrm{O}(2)$, resulting in a Bader net charge of $\mathrm{H}$ in $\mathrm{OH}$ equal to +0.75 e. Another $\mathrm{H}$ on $\mathrm{Au}$ cluster remains negatively charged. Note that formation of the hydrogen anions on the gold surface can influence probability of further hydrogenation reactions catalyzed by the supported gold clusters.

We can conclude that the catalytic activity of gold nanoparticles for $\mathrm{O}_{2}$ dissociation would depend on the electronic structure and the size of the nanoparticles; however in the case of $\mathrm{H}_{2}$ dissociation it will be proportional to the number of gold atoms located in the vicinity of the low coordinated $\mathrm{O}(2)$ atoms at the nanoparticle-surface interface.

\section{Conclusions}

The present theoretical study demonstrates the support effects are very important in the gold nanocatalysis. Even "inert" h-BN support, if it contains vacancy defects, can promote the catalytic properties of gold clusters in oxidation reaction by $\mathrm{O}_{2}$. It is demonstrated that $\mathrm{Au}$ and $\mathrm{Au}_{2}$ interact weakly with the regular defect-free h-BN surface; however they can be trapped effectively by $\mathrm{N}$ or $\mathrm{B}$ vacancy defects in h-BN. Strong adsorption on the surface defects is accompanied by the charge transfer to/from the adsorbate. The value and the sign of the charge accumulated on the adsorbate depend on the adsorption sites. Thus, $\mathrm{V}_{\mathrm{N}}$ donates electrons to the adsorbed $\mathrm{Au}$ and $\mathrm{Au}_{2}$, while $\mathrm{V}_{\mathrm{B}}$ acts as an electron acceptor. The excess of the positive or negative charge on the supported gold clusters can considerably promote their catalytic properties and enhance activation of the adsorbed $\mathrm{O}_{2}$. Our finding leads to a very important conclusion that gold clusters supported on the defected h-BN surface can not be considered as pseudo-free clusters. The support effects have to be taken into account. 
We also demonstrate that the "active" rutile $\mathrm{TiO}_{2}(110)$ support energetically promotes $\mathrm{H}_{2}$ dissociation on gold clusters. For this reaction the conventional charge transfer mechanism does not play an important role. However, adsorption of $\mathrm{H}_{2}$ on $\mathrm{Au}_{n}$ and $\mathrm{Au}_{n} / \mathrm{TiO}_{2}(110)(n=1,2,8,20)$ strongly depends on cluster size, geometric structure, flexibility and interaction with the support material. We demonstrate that the formation of the $\mathrm{OH}$ group near the supported gold cluster is an important condition for $\mathrm{H}_{2}$ dissociation. We have shown that the active sites towards $\mathrm{H}_{2}$ dissociation on the supported $\mathrm{Au}_{n}$ are located at corners and edges of the gold cluster in the vicinity of the low coordinated oxygen atoms on $\mathrm{TiO}_{2}(110)$. Therefore catalytic activity of a gold nanoparticle supported on the rutile $\mathrm{TiO}_{2}(110)$ surface is proportional to the length of the perimeter interface between the nanoparticle and the support, in accordance with the recent experimental findings [38].

\section{Acknowledgements}

This work was supported by the Global COE Program (Project No. B01: Catalysis as the Basis for Innovation in Materials Science) from the Ministry of Education, Culture, Sports, Science and Technology, Japan; the Grant-in-Aid for the Project on Strategic Utilization of Elements; the JSPS Grant-in-Aid for Scientific Research C; and the Collaborative Research Program 2011, Information Initiative Center, Hokkaido University, Sapporo, Japan. The computations were partly performed using the Research Center for Computational Science, Okazaki, Japan.

\section{References}

1. Haruta, M.; Kobayashi, T.; Sano, H.; Yamada, N. Novel gold catalysts for the oxidation of carbon monoxide at a temperature far below $0{ }^{\circ} \mathrm{C}$. Chem. Lett. 1987, 16, 405-408.

2. Haruta, M. When gold is not noble: Catalysis by nanoparticles. Chem. Rec. 2003, 3, 75-87.

3. Thompson, D.T. Using gold nanoparticles for catalysis. Nanotoday 2007, 2, 40-43.

4. Nanocatalysis; Heiz, U., Landman, U., Eds.; Springer: Berlin, Heidelberg, Germany, 2007.

5. Haruta, M. Size- and support-dependency in the catalysis of gold. Catal. Today 1997, 36, 153-166.

6. Turner, M.; Golovko, V.B.; Vaughan, O.P.H.; Abdulkin, P.; Berenguer-Murcia, A.; Tikhov, M.S.; Johnson, B.F.G.; Lambert, R.M. Selective oxidation with dioxygen by gold nanoparticle catalysts derived from 55-atom clusters. Nature 2008, 454, 981-984.

7. Hughes, M.D.; Xu, Y.J.; Jenkins, P.; McMorn, P.; Landon, P.; Enache, D.I.; Carley, A.F.; Attard, G.A.; Hutchings, G.J.; King, F.; Stitt, E.H.; Johnston, P.; Griffin, K.; Kiely, C.J. Tunable gold catalysts for selective hydrocarbon oxidation under mild conditions. Nature 2005, 437, 1132-1135.

8. Tsunoyama, H.; Sakurai, H.; Negishi, Y.; Tsukuda, T. Size-specific catalytic activity of polymer-stabilized gold nanoclusters for aerobic alcohol oxidation in water. J. Am. Chem. Soc. 2005, 127, 9374-9375.

9. Landon, P.; Collier, P.J.; Papworth, A.J.; Kiely, C.J.; Hutchings, G. Direct formation of hydrogen peroxide from $\mathrm{H}_{2} / \mathrm{O}_{2}$ using a gold catalyst. Chem. Commun. 2002, 2058-2059; doi:10.1039/B205248M. 
10. Lyalin, A.; Taketsugu, T. Cooperative adsorption of $\mathrm{O}_{2}$ and $\mathrm{C}_{2} \mathrm{H}_{4}$ on small gold clusters. J. Phys. Chem. C 2009, 113, 12930-12934.

11. Lyalin, A.; Taketsugu, T. Reactant-promoted oxygen dissociation on gold clusters. J. Phys. Chem. Lett. 2010, 1, 1752-1757.

12. Jia, J.; Haraki, K.; Kondo, J.N.; Domen, K.; Tamaru, K. Selective hydrogenation of acetylene over $\mathrm{Au} / \mathrm{Al}_{2} \mathrm{O}_{3}$ catalyst. J. Phys. Chem. B 2000, 104, 11153-11156.

13. Choudhary, T.V.; Sivadinarayana, C.; Datye, A.K.; Kumar, D.; Goodman, D.W. Acetylene hydrogenation on Au-based catalysts. Catal. Lett. 2003, 86, 1-8.

14. Bailie, J.E.; Hutchings, G.J. Promotion by sulfur of gold catalysts for crotyl alcohol formation from crotonaldehyde hydrogenation. Chem. Commun. 1999, 2151-2152; doi:10.1039/A906538E.

15. Schimpf, S.; Martin Lucas, M.; Mohra, C.; Rodemerck, U.; Brückner, A.; Radnik, J.; Hofmeister, H.; Claus, P. Supported gold nanoparticles: In-depth catalyst characterization and application in hydrogenation and oxidation reactions. Catal. Today 2002, 72, 63-78.

16. Okumura, M.; Akita, T.; Haruta, M. Hydrogenation of 1,3-butadiene and of crotonaldehyde over highly dispersed au catalysts. Catal. Today 2002, 74, 265-269.

17. Mohr, C.; Hofmeister, H.; Radnik, J.; Claus, P. Identification of active sites in gold-catalyzed hydrogenation of acrolein. J. Am. Chem. Soc. 2003, 125, 1905-1911.

18. Zanella, R.; Louis, C.; Giorgio, S.; Touroude, R. Crotonaldehyde hydrogenation by gold supported on $\mathrm{TiO}_{2}$ : Structure sensitivity and mechanism. J. Catal. 2004, 223, 328-339.

19. Claus, P. Heterogeneously catalysed hydrogenation using gold catalysts. Appl. Catal. A Gen. 2005, 291, 222-229.

20. Zhu, Y.; Qian, H.; Drake, B.A.; Jin, R. Atomically precise $\mathrm{Au}_{25}(\mathrm{SR})_{18}$ nanoparticles as catalysts for the selective hydrogenation of $\alpha, \beta$-unsaturated ketones and aldehydes. Angew. Chem. Int. Ed. 2010, 49, 1295-1298.

21. Zhu, Y.; Wu, Z.; Gayathri, C.; Qian, H.; Gil, R.R.; Jin, R. Exploring stereoselectivity of $\mathrm{Au}_{25}$ nanoparticle catalyst for hydrogenation of cyclic ketone. J. Catal. 2010, 271, 155-160.

22. Herzing, A.A.; Kiely, C.J.; Carley, A.F.; Landon, P.; Hutchings, G.J. Identification of active gold nanoclusters on iron oxide supports for CO oxidation. Science 2008, 321, 1331-1335.

23. Rodríguez-Vázquez, M.J.; Blanco, M.C.; Lourido, R.; Vázquez-Vázquez, C.; Pastor, E.; Planes, G.A.; Rivas, J.; López-Quintela, M.A. Synthesis of atomic gold clusters with strong electrocatalytic activities. Langmuir 2008, 24, 12690-12694.

24. Heiz, U.; Sanchez, A.; Abbet, S.; Schneider, W.D. Catalytic oxidation of carbon monoxide on monodispersed platinum clusters: Each atom counts. J. Am. Chem. Soc. 1999, 121, 3214-3217.

25. Bonačić-Koutecký, V.; Mitrić, R.; Bürgel, C.; Bchäfer-Bung, B. Cluster properties in the regime in which each atom counts. Comput. Mater. Sci. 2006, 35, 151-157.

26. Hvolbæk, B.; Janssens, T.V.W.; Clausen, B.S.; Falsig, H.; Christensen, C.H.; Nørskov, J.K. Catalytic activity of Au nanoparticles. Nanotoday 2007, 2, 14-18.

27. Lang, S.M.; Bernhardt, T.M.; Barnett, R.N.; Yoon, B.; Landman, U. Hydrogen-promoted oxygen activation by free gold cluster cations. J. Am. Chem. Soc. 2009, 131, 8939-8951. 
28. Bürgel, C.; Reilly, N.M.; Johnson, G.E.; Mitrić, R.; Kimble, M.L.; Castleman, A.W., Jr.; Bonačić-Koutecký, V. Influence of charge state on the mechanism of CO oxidation on gold clusters. J. Am. Chem. Soc. 2008, 130, 1694-1698.

29. Coquet, R.; Howard, K.L.; Willock, D.J. Theory and simulation in heterogeneous gold catalysis. Chem. Soc. Rev. 2008, 37, 2046-2076.

30. Ding, X.; Li, Z.; Yang, J.; Hou, J.G.; Zhu, Q. Adsorption energies of molecular oxygen on Au clusters. J. Chem. Phys. 2004, 120, 9594-9600.

31. Fernández, E.; Ordejón, P.; Balbás, L.C. Theoretical study of $\mathrm{O}_{2}$ and $\mathrm{CO}$ adsorption on $\mathrm{Au}_{\mathrm{n}}$ clusters ( $n=5-10)$. Chem. Phys. Lett. 2005, 408, 252-257.

32. Häkkinen, H.; Landman, U. Gas-phase catalytic oxidation of $\mathrm{CO}$ by $\mathrm{Au}_{2}^{-}$. J. Am. Chem. Soc. 2001, 123, 9704-9705.

33. Yoon, B.; Häkkinen, H.; Landman, U. Interaction of $\mathrm{O}_{2}$ with gold clusters: Molecular and dissociative adsorption. J. Phys. Chem. A 2003, 107, 4066-4071.

34. Socaciu, L.D.; Hagen, J.; Bernhardt, T.M.; Wöste, L.; Heiz, U.; Häkkinen, H.; Landman, U. Catalytic $\mathrm{CO}$ oxidation by free $\mathrm{Au}_{2}^{-}$: Experiment and theory. J. Am. Chem. Soc. 2003, 125, 10437-10445.

35. Häkkinen, H.; Abbet, S.; Sanchez, A.; Heiz, U.; Landman, U. Structural, electronic, and impurity-doping effects in nanoscale chemistry: Supported gold nanoclusters. Angew. Chem. Int. Ed. 2003, 42, 1297-1300.

36. Hutchings, G.J.; Hall, M.S.; Carley, A.F.; Landon, P.; Solsona, B.E.; Kiely, C.J.; Herzing, A.; Makkee, M.; Moulijn, J.A.; Overweg, A.; Fierro-Gonzalez, J.C.; Guzman, J.; Gates, B.C. Role of gold cations in the oxidation of carbon monoxide catalyzed by iron oxide-supported gold. J. Catal. 2006, 242, 71-81.

37. Lyalin, A.; Taketsugu, T. Adsorption of ethylene on neutral, anionic, and cationic gold clusters. J. Phys. Chem. C 2010, 114, 2484-2493.

38. Fujitani, T.; Nakamura, I.; Akita, T.; Okumura, M.; Haruta, M. Hydrogen dissociation by gold clusters. Angew. Chem. Int. Ed. 2009, 48, 9515-9518.

39. Okumura, M.; Tsubota, S.; Haruta, M. Preparation of supported gold catalysts by gas-phase grafting of gold acethylacetonate for low-temperature oxidation of $\mathrm{CO}$ and of $\mathrm{H}_{2}$. J. Mol. Catal. A Chem. 2003, 199, 73-84.

40. Sanchez, A.; Abbet, S.; Heiz, U.; Schneider, W.D.; Hakkinen, H.; Barnett, R.N.; Landman, U. When gold is not noble: Nanoscale gold catalysts. J. Phys. Chem. A 1999, 103, 9573-9578.

41. Yoon, B.; Häkkinen, H.; Landman, U.; Wörz, A.S.; Antonietti, J.M.; Abbet, S.; Judai, K.; Heiz, U. Charging effects on bonding and catalyzed oxidation of $\mathrm{CO}$ on $\mathrm{Au}_{8}$ clusters on $\mathrm{MgO}$. Science 2005, 307, 403-407.

42. Zhang, C.; Yoon, B.; Landman, U. Predicted oxidation of CO catalyzed by Au nanoclusters on a thin defect-free $\mathrm{MgO}$ film supported on a Mo(100) surface. J. Am. Chem. Soc. 2007, 129, 2228-2229.

43. Sterrer, M.; Risse, T.; Pozzoni, U.; Giordano, L.; Heyde, M.; Rust, H.; Pacchioni, G.; Freund, H. Control of the charge state of metal atoms on thin MgO films. Phys. Rev. Lett. 2007, 98, 096107:1-096107:4. 
44. Frondelius, P.; Häkkinen, H.; Honkala, K. Adsorption of gold clusters on metal-supported MgO: Correlation to electron affinity of gold. Phys. Rev. B 2007, 76, 073406:1-073406:4.

45. Honkala, K.; Häkkinen, $\mathrm{H}$. Au adsorption on regular and defected thin $\mathrm{MgO}(100)$ films supported by Mo. J. Phys. Chem. C 2007, 111, 4319-4327.

46. Harding, C.; Habibpour, V.; Kunz, S.; Farnbacher, A.N.S.; Heiz, U.; Yoon, B.; Landman, U. Control and manipulation of gold nanocatalysis: Effects of metal oxide support thickness and composition. J. Am. Chem. Soc. 2009, 131, 538-548.

47. Arenal, R.; Stéphan, O.; Kociak, M.; Taverna, D.; Loiseau, A.; Colliex, C. Electron energy loss spectroscopy measurement of the optical gaps on individual boron nitride single-walled and multiwalled nanotubes. Phys. Rev. Lett. 2005, 95, 127601:1-127601:4.

48. Golberg, D.; Bando, Y.; Huang, Y.; Terao, T.; Mitome, M.; Tang, C.; Zhi, C. Boron nitride nanotubes and nanosheets. ACS Nano 2010, 4, 2979-2993.

49. Green, I.X.; Tang, W.; Neurock, M.; Yates, J.T. Low-temperature catalytic $\mathrm{H}_{2}$ oxidation over $\mathrm{Au}$ nanoparticle $/ \mathrm{TiO}_{2}$ dual perimeter sites. Angew. Chem. Int. Ed. 2011, 50, 10186-10189.

50. Boronat, M.; Illas, F.; Corma, A. Active sites for $\mathrm{H}_{2}$ adsorption and activation in $\mathrm{Au} / \mathrm{TiO}_{2}$ and the role of the support. J. Phys. Chem. A 2009, 113, 3750-3757.

51. Florez, E.; Gomez, T.; Liu, P.; Rodríguez, J.A.; Illas, F. Hydrogenation reactions on Au/TiC(001): Effects od Au-C interactions on the dissociation of $\mathrm{H}_{2}$. ChemCatChem 2010, 2, 1219-1222.

52. Lyalin, A.; Taketsugu, T. A computational investigation of $\mathrm{H}_{2}$ adsorption and dissociation on $\mathrm{Au}$ nanoparticles supported on $\mathrm{TiO}_{2}$ surface. Faraday Discuss. 2011, 152, 185-201.

53. Wu, Z; Cohen, R.E. More accurate generalized gradient approximation for solids. Phys. Rev. $B$ 2006, 73, 235116:1-235116:6.

54. Perdew, J.P.; Burke, K.; Ernzerhof, M. Generalized gradient approximation made simple. Phys. Rev. Lett. 1996, 77, 3865-3868.

55. Tran, F.; Laskowski, R.; Blaha, P.; Schwarz, K. Performance on molecules, surfaces, and solids of the Wu-Cohen GGA exchange-correlation energy functional. Phys. Rev. B 2007, 75, 115131:1-115131:14.

56. Artacho, E.; Sánchez-Portal, D.; Ordejón, P.; García, A.; Soler, J.M. Linear-scaling ab-initio calculations for large and complex systems. Phys. Status Solidi B 1999, 215, 809-817.

57. Junquera, J.; Paz, O.; Sánchez-Portal, D.; Artacho, E. Numerical atomic orbitals for linear-scaling calculations. Phys. Rev. B 2001, 64, 235111:1-235111:9.

58. Nelder, J.A.; Mead, R. A simplex method for function minimization. Comput. J. 1965, 7, 308-313.

59. Troullier, N.; Martins, J.L. Efficient pseudopotentials for plane-wave calculations. Phys. Rev. $B$ 1991, 43, 1993-2006.

60. Kleinman, L.; Bylander, D.M. Efficacious form for model pseudopotentials. Phys. Rev. Lett. 1982, 48, 1425-1428.

61. Monkhorst, H.J.; Pack, J.D. Special points for Brillouin-zone integrations. Phys. Rev. B 1976, 13, 5188-5192.

62. Yoo, C.S.; Akella, J.; Cynn, H.; Nicol, M. Direct elementary reactions of boron and nitrogen at high pressures and temperatures. Phys. Rev. B 1997, 56, 140-146. 
63. Burdett, J.K.; Hughbanks, T.; Miller, G.J.; Richardson, J.W., Jr.; Smith, J.V. Structural-electronic relationships in inorganic solids: Powder neutron diffraction studies of the rutile and anatase polymorphs of titanium dioxide at 15 and 295 K. J. Am. Chem. Soc. 1987, 109, 3639-3646.

64. Muscat, J.; Swamy, V.; Harrison, N.M. First-principles calculations of the phase stability of $\mathrm{TiO}_{2}$. Phys. Rev. B 2002, 65, 224112:1-224112:15.

65. Solov'yov, I.A.; Solov'yov, A.V.; Greiner, W.; Koshelev, A.; Shutovich, A. Cluster growing process and a sequence of magic numbers. Phys. Rev. Lett. 2003, 90, 053401:1-053401:4.

66. Lyalin, A.; Solov'yov, I.A.; Solov'yov, A.V.; Greiner, W. Evolution of the electronic and ionic structure of Mg clusters with increase in cluster size. Phys. Rev. A 2003, 67, 063203:1-063203:13.

67. Lyalin, A.; Solov'yov, A.V.; Greiner, W. Structure and magnetism of lanthanum clusters. Phys. Rev. A 2006, 74, 043201:1-043201:10.

68. Lyalin, A.; Solov'yov, I.A.; Greiner, W. Interplay of electronic and geometry shell effects in properties of neutral and charged Sr clusters. Phys. Rev. A 2007, 75, 053201:1-053201:13.

69. Ohno, K.; Maeda, S. A scaled hypersphere search method for the topography of reaction pathways on the potential energy surface. Chem. Phys. Lett. 2004, 384, 277-282.

70. Maeda, S.; Ohno, K. Global mapping of equilibrium and transition structures on potential energy surfaces by the scaled hypersphere search method: Applications to ab initio surfaces of formaldehyde and propyne molecules. J. Phys. Chem. A 2005, 109, 5742-5753.

71. Ohno, K.; Maeda, S. Global reaction route mapping on potential energy surfaces of formaldehyde, formic acid, and their metal-substituted analogues. J. Phys. Chem. A 2006, 110, 8933-8941.

72. Fernández, E.; Soler, J.M.; Garzón, I.L.; Balbás, L.C. Trends in the structure and bonding of noble metal clusters. Phys. Rev. B 2004, 70, 165403:1-165403:14.

73. Walker, A.W. Structure and energetics of small gold nanoclusters and their positive ions. J. Chem. Phys. 2005, 122, 094310:1-094310:12.

74. Xiao, L.; Tollberg, B.; Hu, X.; Wang, L. Structural study of gold clusters. J. Chem. Phys. 2006, 124, 094310:1-094310:10.

75. Häkkinen, H. Atomic and electronic structure of gold clusters: Understanding flakes, cages and superatoms from simple concept. Chem. Soc. Rev. 2008, 37, 1847-1859.

76. Sánchez-Portal, D.; Ordejón, P.; Artacho, E.; Soler, J.M. Density-functional method for very large systems with LCAO basis sets. Int. J. Quantum Chem. 1997, 65, 453-461.

77. Soler, J.M.; Artacho, E.; Gale, J.D.; García, A.; Junquera, J.; Ordejón, P.; Sánchez-Portal, D. The siesta method for ab initio order-N materials simulation. J. Phys. Condens. Matter 2002, 14, 2745-2779.

78. Sánchez-Portal, D.; Ordejón, P.; Canadell, E. Computing the properties of materials from first principles with siesta. Struct. Bond. 2004, 113, 103-170.

79. Bader, R. Atoms in Molecules: A Quantum Theory; Oxford University Press: New York, NY, USA, 1990.

80. Henkelman, G.; Arnaldsson, A.; Jònsson, H. A fast and robust algorithm for Bader decomposition of charge density. Comput. Mater. Sci. 2006, 36, 354-360.

81. Kokalj, A. Computer graphics and graphical user interfaces as tools in simulations of matter at the atomic scale. Comput. Mater. Sci. 2003, 28, 155-168. 
82. Huber, K.P.; Herzberg, G. Molecular Spectra and Molecular Structure Constants of Diatomic Molecules; Van Nostrand Reinhold: New York, NY, USA, 1979.

83. Furthmüller, J.; Hafner, J.; Kresse, G. Ab initio calculation of the structural and electronic properties of carbon and boron nitride using ultrasoft pseudopotentials. Phys. Rev. B 1994, 50, 15606-15622.

84. Orellana, W.; Chacham, H. Stability of native defects in hexagonal and cubic boron nitride. Phys. Rev. B 2001, 63, 125205:1-125205:7.

85. Kuzubov, A.A.; Serzhantova, M.V.; Fedorov, A.S.; Tomilin, F.N.; Kozhevnikova, T.A. Theoretical study of vacancies and adatoms in white graphene. JETP Lett. 2011, 93, 335-338.

86. Si, M.S.; Li, J.Y.; Shi, H.G.; Niu, X.N.; Xue, D.S. Divacancies in graphitic boron nitride sheets. Europhys. Lett. 2009, 86, 46002:1-46002:6.

87. Zobelli, A.; Ewels, C.P.; Gloter, A.; Seifert, G.; Stephan, O.; Csillag, S.; Colliex, C. Defective structure of BN nanotubes: From single vacancies to dislocation lines. Nano Lett. 2006, 6, 1955-1960.

88. Jin, C.; Lin, F.; Suenaga, K.; Iijima, S. Fabrication of a freestanding boron nitride single layer and its defect assignments. Phys. Rev. Lett. 2009, 102, 195505:1-195505:4.

89. Yin, L.C.; Cheng, H.M.; Saito, R. Triangle defect states of hexagonal boron nitride atomic layer: Density functional theory calculations. Phys. Rev. B 2010, 81, 153407:1-153407:4.

90. Corso, M.; Auwärter, W.; Muntwiler, M.; Tamai, A.; Greber, T.; Osterwalder, J. Boron nitride nanomesh. Science 2004, 303, 217-220.

91. Laskowski, R.; Blaha, P.; Schwarz, K. Bonding of hexagonal BN to transition metal surfaces: An ab initio density-functional theory study. Phys. Rev. B 2008, 78, 045409:1-045409:10.

92. Inorganic Chemistry; Wiberg, N., Holleman, A.F., Wiberg, E., Eds.; Academic Press: Waltham, MA, USA, 2001.

93. Ramamoorthy, M.; Vanderbilt, D.; King-Smith, R.D. First-principles calculations of the energetics of stoichiometric $\mathrm{TiO}_{2}$ surfaces. Phys. Rev. B 1994, 49, 16721-16727.

94. Perron, H.; Domain, C.; Roques, J.; Drot, R.; Simoni, E.; Catalette, H. Optimisation of accurate rutile $\mathrm{TiO}_{2}(110),(100)$, (101) and (001) surface models from periodic DFT calculations. Theor. Chem. Acc. 2007, 117, 565-574.

95. Lyalin, A.; Taketsugu, T. Catalitic activity of gold clusters. AIP Conf. Proc. 2009, 1197, 65-75.

96. Barrio, L.; Liu, P.; Rodríguez, J.A.; Campos-Martín, J.M.; Fierro, J.L.G. A density functional theory study of the dissociation of $\mathrm{H}_{2}$ on gold clusters: Importance of fluxionality and ensemble effects. J. Chem. Phys. 2006, 125, 164715:1-164715:5.

(c) 2011 by the authors; licensee MDPI, Basel, Switzerland. This article is an open access article distributed under the terms and conditions of the Creative Commons Attribution license (http://creativecommons.org/licenses/by/3.0/). 